\title{
VIABILIDADE ECONÔMICA DA TERMINAÇÃO DE OVINOS EM CAPIM-TANZÂNIA COM QUATRO NÍVEIS DE SUPLEMENTAÇÃO CONCENTRADA
}

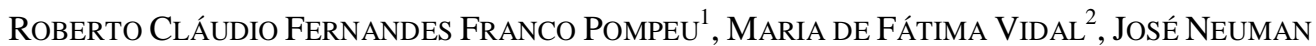 \\ Miranda Neiva ${ }^{3}$, Magno José Duarte CÂNDIDO ${ }^{4}$, Marcos Cláudio PinHeiro Rogério ${ }^{5}$, \\ RODRIGO GREGÓRIO DA SILVA ${ }^{6}$
}

\footnotetext{
${ }^{1}$ Pesquisador da Empresa Brasileira de Pesquisa Agropecuária, Embrapa Caprinos e Ovinos, Sobral, CE rpompeu@cnpc.embrapa.br

${ }^{2}$ Pesquisadora do Banco do Nordeste do Brasil/FUNDECI, Fortaleza, CE

${ }^{3}$ Professor Doutor, Departamento de Medicina Veterinária e Zootecnia da Universidade Federal do Tocantins, Araguaína, TO

${ }^{4}$ Professor Doutor, Departamento de Zootecnia da Universidade Federal do Ceará, Fortaleza, CE

${ }^{5}$ Pesquisador da Empresa Brasileira de Pesquisa Agropecuária, Embrapa Caprinos e Ovinos, Sobral, CE

${ }^{6}$ Professor Doutor, Instituto Federal de Educação, Ciência e Tecnologia - IFCE, Campus Avançado do Tauá, Tauá, CE
}

\section{RESUMO}

Avaliou-se a viabilidade econômica da terminação de ovinos em pastagem de capim-tanzânia sob lotação rotativa com quatro níveis de suplementação concentrada (0; 0,$6 ; 1,2$ e 1,8\% PV), dois sistemas de separação do rebanho (cerca elétrica e cerca de tela) e três tamanhos de áreas (1,0; 3,0 e 5,0 ha). A análise foi feita com vistas a determinar as condições mínimas necessárias para tornar o empreendimento viável. Foram avaliadas a receita líquida, a relação benefício/custo, o valor presente líquido e a taxa interna de retorno, adotando uma taxa de juros de 8,75\% ao ano. Foram estimados o custo total de implantação e manutenção para cada sistema, sendo orçados de acordo com os preços no mercado de Fortaleza/CE. Para o cálculo da receita total, foram considerados preços de venda entre R\$2,60 e 3,20/kg PV. A exploração de 1,0 ha se mostrou economicamente inviável para os dois tipos de sistemas testados. Para ambos os sistemas, observou-se que aqueles que utilizaram cerca de tela apresentaram maior custo em relação à cerca elétrica. Para os sistemas que utilizaram suplementação, os dados mostraram que só é viável suplementar os animais quando o preço pago pelo produto for superior a $\mathrm{R} \$ 3,00 / \mathrm{kg} \mathrm{PV}$, em alguns casos com áreas superiores a 5 ha.

PALAVRAS-CHAVE: análise de rentabilidade; Panicum maximum; sistema de produção; suplementação concentrada; taxa interna de retorno.

\section{ECONOMIC VIABILITY OF FINISHING SHEEP ON TANZANIA PASTURE UNDER INTERMITTENT GRAZING WITH FOUR CONCENTRATE SUPPLEMENTATION LEVELS}

\section{ABSTRACT}

The economic viability of finishing sheep on Tanzania grass under intermittent grazing was evaluated with four concentrate supplementation levels $(0 ; 0.6 ; 1.2$ and $1.8 \%$ LW), two herd separation systems (electric and net fence) and three pasture sizes (1.0; 3.0 and 5.0 ha). The analysis was carried out to determine the minimal necessary conditions to have a viable business. Net income, benefitcost ratio, net present value and internal rate of return with an interest of rate of $8.75 \%$ per year were verified. The total implantation cost and maintenance to each system 
was estimated according to Fortaleza/CE market. Sale price between R\$ 2.60 to $3.20 / \mathrm{kg} \mathrm{LW}$ was considered to estimate total budget. The pasture sized 1.0 ha was economically unviable for both kinds of system tested. The system with net fence was more expensive than the one with electric fence. For the systems with supplementation, data showed viability only for a sale price above $\mathrm{R} \$ 3.00 / \mathrm{kg} \mathrm{LW}$ and, in some cases, in areas above 5.0 ha.

KEYWORDS: concentrate supplementation; internal rate of return; Panicum maximum; profitability analysis; production system.

\section{INTRODUÇÃO}

No Brasil, particularmente na região Nordeste, a demanda por carne ovina aumentou significativamente nos últimos anos, levando os produtores rurais a investir cada vez mais em tecnologias que possam melhorar a produtividade e a qualidade dos rebanhos para atender sua demanda interna, uma vez que cerca de $50 \%$ da carne ovina consumida é importada do Uruguai, Argentina e Nova Zelândia (ALMEIDA JÚNIOR et al., 2004).

Os sistemas de produção de carne no país caracterizam-se pela dependência quase que exclusiva de pastagens, principalmente compostas de gramíneas tropicais. Isso resulta em menores custos de produção; entretanto, a utilização exclusiva de pastagens como alimento animal apresenta muitas vezes resultados inviáveis economicamente, devido à forma como essas pastagens são manejadas (EUCLIDES FILHO, 2004).

VIDAL et al.(2006) e SILVA et al. (2007), trabalhando com produção intensiva (adubação e irrigação) de ovinos sem padrão racial definido (SPRD), em pastagem de capim-tanzânia sob três períodos de descanso (17, 26 e 37 dias), no Semi-árido Nordestino, observaram que, sob o ponto de vista econômico, biológico e ambiental, o período de descanso de 26 dias a partir de 5,0 ha elevou a estabilidade do sistema e do retorno econômico. Vale salientar que apesar de o sistema ter suportado uma taxa de lotação de 8,0 UA/ha, não houve comprometimento da estrutura da pastagem.

Portanto, para que os sistemas de produção da pecuária de corte sejam competitivos, faz-se necessário manter taxas de ganho de peso razoáveis durante a estação seca, principalmente no Semi-árido Brasileiro, e para isso há necessidade de se utilizar algum tipo de suplemento alimentar para manter a mesma carga animal na área sem prejudicar a estrutura da pastagem e o desempenho animal. $\mathrm{O}$ uso da suplementação permite regular a oferta de alimento e aumentar o rendimento animal, pois, à medida que se aumenta a quantidade de suplemento, menor é a contribuição da pastagem na alimentação do rebanho, dependendo do tipo de suplemento, aumentando a capacidade de suporte das pastagens (EUCLIDES, 2000). Dessa forma, a duração e o tipo de suplemento a ser empregado dependerão da região, do custo e do sistema de produção
(CARVALHO et al., 2010).

EUCLIDES et al. (1998), trabalhando com desempenho de novilhos nos cerrados com suplementação alimentar durante a primeira seca do ano, a segunda seca do ano, a primeira e a segunda seca do ano e suplementado na primeira seca e confinado na segunda seca, comparados aos animais não suplementados, observaram que a suplementação durante o período seco reduziu a idade de abate de cinco a treze meses, demonstrando a viabilidade econômica dessa prática de manejo até mesmo quando combinada com o confinamento.

No Semi-árido Brasileiro, são escassas as informações sobre a viabilidade econômica de diferentes sistemas de produção na terminação de ovinos. Nesse contexto, objetivou-se com esta pesquisa verificar a viabilidade econômica de ovinos terminados em pastagem de capim-tanzânia sob lotação rotativa com quatro níveis de suplementação concentrada, dois sistemas de contenção do rebanho e três tamanhos de áreas.

\section{MATERIAL E MÉTODOS}

Os dados experimentais foram coletados na Fazenda Experimental do Vale do Curú, situada no município de Pentecoste - Ceará - e no Departamento de Zootecnia do Centro de Ciências Agrárias (CCA) da Universidade Federal do Ceará (UFC). Os dados foram obtidos do trabalho "Morfofisiologia do dossel e desempenho bioeconômico de ovinos em capimtanzânia sob lotação rotativa com quatro níveis de suplementação concentrada”, desenvolvido por POMPEU (2006).

O município de Pentecoste está localizado nas latitudes $3^{\circ} 40^{\prime}$ a $3^{\circ} 51^{\prime} 18^{\prime \prime}$ sul e longitudes $39^{\circ} 10^{\prime} 19^{\prime \prime}$ e $39^{\circ} 18^{\prime} 13$ oeste numa região cujo clima, segundo a classificação de Köeppen, é do tipo BSw’h’, semi-árido quente, com precipitação média anual de $806,5 \mathrm{~mm}$, distribuída no período de janeiro a abril. O solo da área experimental é classificado como Neossolo flúvico (solos aluviais) (EMBRAPA, 1999) de textura argilosa. Os dados referentes às condições de temperaturas médias, máximas e mínimas, umidade relativa do ar média, radiação e insolação média do período experimental (setembro a dezembro de 2004) foram de $27,1^{\circ} \mathrm{C}, \quad 65,5 \%, \quad 27,3 \mathrm{MJ} / \mathrm{m}^{2}$.dia e $9,3 \mathrm{~h}$, 
respectivamente.

Foram utilizados 86 ovinos sem padrão racial definido (SPRD), sendo oito animais por tratamento, resultando num total de 32 animais de prova adquiridos em fazendas comerciais, com idades variadas, chegando até um ano e meio e com peso médio inicial de $24,14 \mathrm{~kg}$, e identificados com brincos. A escolha desses animais foi realizada por meio de sorteio. Os demais ovinos foram sorteados e utilizados como animais de equilíbrio.

Foram avaliados quatro níveis de suplementação para ovinos pastejando Panicum maximum cv. Tanzânia sob lotação rotativa. Os níveis de suplementação corresponderam a 0,0; 0,6; 1,2 e 1,8\% do peso vivo (PV) dos ovinos por dia, considerando uma capacidade de consumo diária de matéria seca (MS) de 3,6\% PV. O dimensionamento dos piquetes foi efetuado de modo a garantir uma oferta de forragem de 7,2\% PV (HODGSON, 1990), considerando uma taxa de crescimento cultural (TCC) de $140 \mathrm{~kg}$ MS/ha $\mathrm{x}$ dia, conforme preconizado por SILVA (2004).

O delineamento utilizado foi inteiramente casualizado, com quatro níveis de suplementação e oito repetições (ovinos), envolvendo 32 piquetes, sendo oito por tratamento.

O método de pastejo adotado foi o de lotação rotativa, com taxa de lotação variável "put and take", descrita por MOTT \& LUCAS (1952), citados por FISHER (2000). A área total para cada tratamento, de $1.472 \mathrm{~m}^{2}$, foi dividida com cerca do tipo tela campestre em oito piquetes, perfazendo um total de $183,6 \mathrm{~m}^{2}$ por piquete e totalizando $5.888,0 \mathrm{~m}^{2}$ de área experimental (32 piquetes). O restante da área (aproximadamente $9.000 \mathrm{~m}^{2}$ ) foi utilizado como pasto de reserva, para acondicionamento dos animais de equilíbrio. Cada piquete foi provido de comedouros, bebedouros e sombrites de $8,0 \mathrm{~m}^{2}$, com $25 \%$ de transmitância de luz. O período de descanso (21 dias) correspondeu ao tempo necessário para a expansão de duas novas folhas por perfilho, conforme estimado por Silva (2004) e o período de pastejo foi de três dias. Os ovinos extras foram utilizados, quando necessário, para garantir o rebaixamento da vegetação para uma altura residual de 28,0 cm, correspondente a um índice de área foliar de 1,0 (SILVA, 2004), ao final do terceiro dia de pastejo.

Durante o período de descanso, avaliaram-se as características morfofisiológicas do capim-tanzânia. A pesagem dos animais foi realizada a cada 12 dias. Os animais de prova de cada tratamento foram conduzidos ao centro de manejo na passagem do último dia de pastejo do quarto piquete para o primeiro dia de pastejo do quinto piquete e na passagem do último dia de pastejo do último piquete de um ciclo para o primeiro dia de pastejo do primeiro piquete do ciclo seguinte.

Para a análise econômica foi considerada a terminação de ovinos machos castrados com peso vivo inicial de $20 \mathrm{~kg}$ e com o ganho médio diário (GMD), taxa de lotação (TLO) e rendimento de peso vivo (RPV) estimados pela equação de regressão para cada tratamento. A estimativa do GMD, da TLO e do RPV de cada tratamento foi de 76,7 g/ovino x dia, 69,0 ovinos/ha e $1907 \mathrm{~kg} \mathrm{PV/hax} \mathrm{ano} \mathrm{(animais} \mathrm{não}$ suplementados); 101,8 g/ovino x dia, 68,0 ovinos/ha e $2483 \mathrm{~kg}$ PV/ha x ano (animais suplementados ao nível de 0,6\% PV); 117,6 g/ovino x dia, 71,0 ovinos/ha e $3058 \mathrm{~kg}$ PV/ha x ano (animais suplementados ao nível de 1,2\% PV); e, 124,0 g/ovino x dia, 77,0 ovinos/ha e $3633 \mathrm{~kg}$ PV/ha $\mathrm{x}$ ano (animais suplementados ao nível de 1,8\% PV) (POMPEU et al., 2009). A análise foi feita com base nos valores referentes a 1,0; 3,0 e 5,0 ha, com vistas a determinar o nível de produção mínimo para tornar o empreendimento viável. O horizonte da análise foi de 10 anos, período de depreciação do sistema de irrigação. Para cada tratamento, foram comparados os custos da utilização de cerca elétrica e de tela.

A receita bruta (RB) foi calculada pelo produto resultante da produção em $\mathrm{kg} \mathrm{PV}$ pelos diferentes preços por kg PV e pelos três tamanhos de áreas estudados. A receita líquida (RL) foi obtida pela diferença entre a receita bruta (RB) e as despesas ou gastos despendidos pelo sistema durante o processo produtivo.

Foi utilizada como medida de eficiência a relação benefício/custo (B/C), que expressa o desempenho global de todos os fatores de produção.

$$
\mathrm{B} / \mathrm{C}=\Sigma \mathrm{Ri}^{0} / \Sigma\left(\mathrm{Ci}^{0}+\mathrm{I}\right)
$$

Em que:

$\mathrm{R}=$ receita no ano 0 até $\mathrm{o}$ ano $\mathrm{i}$;

$\mathrm{Ci}=$ custos no ano 0 até $\mathrm{o}$ ano $\mathrm{i}$;

$\mathrm{I}=$ investimento.

Foi determinado o valor presente líquido (VPL), que leva em consideração o efeito do tempo sobre os valores monetários (valores reais) utilizando-se a taxa média de juros do mercado (custo de oportunidade do capital). O VPL é a soma de todas as receitas líquidas atualizadas a uma taxa de desconto adequada.

Em que:

$$
V P L=\sum_{i=1}^{n} \frac{(B i-C i)}{(1+j)^{i}}
$$

$\mathrm{j}=$ taxa de desconto;

Bi e Ci = fluxos de benefício e custo no período.

Para cada tratamento, foi calculada a taxa interna de retorno (TIR), que é o percentual de retorno obtido sobre o saldo investido e ainda não recuperado em um projeto de investimento, ou seja, é o percentual que expressa a rentabilidade (retorno) anual média do capital alocado no projeto, durante todo o horizonte de análise do projeto. Matematicamente, a TIR é a taxa de juros que torna o valor presente das entradas de caixa igual ao valor presente das saídas de caixa do projeto de investimento, ou seja, é aquela taxa de juros que 
torna o valor presente líquido igual a zero.

$\mathrm{TIR}=\mathrm{k}$, tal que

$$
\sum_{i=1}^{n} \frac{(B i-C i)}{(1+j)^{i}}=0
$$

Em que:

$\mathrm{j}=$ taxa de desconto;

$\mathrm{Bi}$ e $\mathrm{Ci}$ = fluxos de benefício e custo no período.

A Taxa Interna de Retorno de um investimento pode ser:

- maior do que a Taxa Mínima de Atratividade: significa que o investimento é economicamente atrativo;

- igual à Taxa Mínima de Atratividade: o investimento está economicamente numa situação de indiferença;

- menor do que a Taxa Mínima de Atratividade: o investimento não é economicamente atrativo, pois, seu retorno é superado pelo retorno de um investimento sem risco.

Entre vários investimentos, o melhor será aquele que tiver a maior TIR.

Para o cálculo da depreciação, utilizou-se o método linear ou das cotas fixas, que proporciona depreciação constante, cujo valor é determinado através da seguinte fórmula:

$\mathrm{d}=(\mathrm{vi}-\mathrm{vf}) / \mathrm{n}$

Onde,

$\mathrm{d}=$ depreciação;

$\mathrm{vi}=$ valor inicial;

$\mathrm{vf}=$ valor final, que corresponde ao valor do bem de capital após sua vida útil;

n = número de anos de duração do capital (vida útil).

Para o cálculo dos indicadores foi utilizada uma taxa de juros de 8,75\%, baseada no valor dos encargos a financiamentos a pequenos e médios produtores praticados no mercado. É também uma taxa de juros compatível com o rendimento médio da caderneta de poupança.

Foi estimado o custo total de implantação (preparo do solo, controle inicial das invasoras, plantio, tratos culturais, cercas, sementes, aquisição e montagem do sistema de irrigação etc) e manutenção (energia, compra de animais - R\$ 2,60/kg PV, mão-deobra, tratamento sanitário, irrigação, ração concentrada etc) para cada tratamento. O período considerado para a implantação do sistema (primeiro ano) foi de seis meses, sendo o restante dos meses utilizados para a produção. Todos os custos foram orçados de acordo com os preços no mercado de Fortaleza, CE, para os três tamanhos de áreas avaliadas. Os custos com adubação de manutenção (exclusivamente nitrogenada) foram equivalentes à aplicação de $600 \mathrm{~kg} / \mathrm{ha} \mathrm{x}$ ano.

$\mathrm{O}$ custo do consumo de energia elétrica foi calculado pela média ponderada para os consumidores do Subgrupo A4, no qual se incluem os rurais, com descontos especiais para irrigantes (90\% para a Região Nordeste), nos horários entre 23 e $5 \mathrm{~h}$, conforme a Portaria ${ }^{\circ} 105$ de 03 de abril de 1992 do DNAEE (PINHEIRO et al., 2002, citados por CUTRIM JÚNIOR \& CAMPOS, 2010). Dessa forma, o custo calculado foi de R\$ 0,05/kWh.

Em relação ao gasto com mão-de-obra, foi considerada a manutenção de um funcionário em regime permanente para manejar um rebanho composto por 300 animais (realização das operações de transferência dos animais nos piquetes, aplicação de adubos, limpeza das instalações, manutenção do sistema de irrigação) e a remuneração da mão-de-obra foi correspondente ao salário mínimo (R\$ 300,00) vigente em 2005.

$\mathrm{O}$ centro de manejo foi dimensionado para permitir $1,0 \mathrm{~m}^{2}$ de área coberta por animal além de um pequeno curral de manejo que dispusesse de $0,75 \mathrm{~m}^{2}$ por animal.

Para o cálculo da receita total, foram considerados preços de venda de $\mathrm{R} \$ 2,60 ; 2,80 ; 3,00$ e 3,20 o quilo de peso vivo. A TIR foi determinada apenas para os tratamentos que apresentaram receita líquida positiva. A avaliação dos dados foi realizada por meio de análises descritivas.

\section{RESULTADOS E DISCUSSÃO}

A estimativa de custos de implantação para todos os tratamentos encontra-se nas Tabelas 1 e 2, onde se pode observar que os sistemas que utilizam cerca elétrica apresentaram menor custo de implantação que o sistema que utiliza cerca de tela. Pode-se observar ainda que o custo percentual da cerca torna-se relativamente menos oneroso com o aumento da área, o que evidencia a ineficiência da utilização desse fator de produção na exploração de apenas um hectare. Resultados semelhantes foram relatados por VIDAL et al. (2006) ao compararem dois sistemas de produção de terminação de ovinos em pastagens irrigadas no Semi-árido Brasileiro durante a estação seca. Os itens que mais oneraram os custos de implantação foram a compra de animais e o centro de manejo (sombrites, bebedouros e saleiros), item que inclui tratamento sanitário, mão-de-obra e cochos com média de 44,42\% nos tratamentos com a utilização de cerca elétrica, e de 39,34\% para os tratamentos com a utilização com cerca de tela. Os custos com a irrigação foi o segundo item que mais onerou a estrutura de implantação do sistema, correspondendo em média a $36,85 \%$ para sistema com cerca elétrica e a 32,60\% para sistema com cerca de tela. 
Tabela 1. Custo de implantação da área com pastagem de capim-tanzânia sob lotação rotativa para animais não suplementados e suplementados ao nível de $0,6 \%$ PV, três tamanhos de área e divisão dos piquetes com cerca elétrica e de tela

\begin{tabular}{|c|c|c|c|c|c|c|c|c|c|c|c|c|}
\hline \multirow{4}{*}{$\begin{array}{l}\text { Serviços } \\
\text { e insumos }\end{array}$} & \multicolumn{12}{|c|}{ Animais não suplementados } \\
\hline & \multicolumn{6}{|c|}{ Cerca elétrica } & \multicolumn{6}{|c|}{ Cerca de tela } \\
\hline & \multicolumn{2}{|c|}{1 ha } & \multicolumn{2}{|c|}{3 ha } & \multicolumn{2}{|c|}{5 ha } & \multicolumn{2}{|c|}{1 ha } & \multicolumn{2}{|c|}{3 ha } & \multicolumn{2}{|c|}{5 ha } \\
\hline & $\mathrm{R} \$$ & $\%$ & $\mathrm{R} \$$ & $\%$ & $\mathrm{R} \$$ & $\%$ & $\mathrm{R} \$$ & $\%$ & $\mathrm{R} \$$ & $\%$ & $\mathrm{R} \$$ & $\%$ \\
\hline Preparo do solo & 455,00 & 3,02 & $1.365,00$ & 3,86 & $2.275,00$ & 4,09 & 455,00 & 2,72 & $1.365,00$ & 3,39 & $2.275,00$ & 3,57 \\
\hline Sementes & 60,00 & 0,40 & 180,00 & 0,51 & 300,00 & 0,54 & 60,00 & 0,36 & 180,00 & 0,45 & 300,00 & 0,47 \\
\hline Plantio & 362,50 & 2,41 & $1.087,50$ & 3,08 & $1.812,50$ & 3,26 & 362,50 & 2,17 & $1.087,50$ & 2,70 & $1.812,50$ & 2,85 \\
\hline Tratos culturais & 420,00 & 2,79 & $1.260,00$ & 3,57 & $2.100,00$ & 3,78 & 420,00 & 2,52 & $1.260,00$ & 3,13 & $2.100,00$ & 3,30 \\
\hline Irrigação & $5.086,42$ & 33,81 & $13.818,46$ & 39,11 & $21.928,51$ & 39,45 & $5.086,42$ & 30,46 & $13.818,46$ & 34,32 & $21.928,51$ & 34,44 \\
\hline Cercas & $1.943,23$ & 12,92 & $2.515,33$ & 7,12 & $3.187,21$ & 5,73 & $3.599,20$ & 21,55 & $7.446,00$ & 18,49 & $11.282,00$ & 17,72 \\
\hline Animais e C.M. ${ }^{1}$ & $6.715,43$ & 44,64 & $15.106,29$ & 42,75 & 23.977,15 & 43,14 & $6.715,43$ & 40,22 & $15.106,29$ & 37,52 & 23.977,15 & 37,66 \\
\hline \multirow[t]{2}{*}{ TOTAL } & $15.042,58$ & 100,00 & $35.332,58$ & 100,00 & $55.580,37$ & 100,00 & $16.698,55$ & 100,00 & $40.263,25$ & 100,00 & $63.675,16$ & 100,00 \\
\hline & \multicolumn{12}{|c|}{ Animais suplementados ao nível de $0,6 \%$ PV } \\
\hline \multirow{2}{*}{$\begin{array}{l}\text { Serviços } \\
\text { e insumos }\end{array}$} & \multicolumn{2}{|c|}{1 ha } & \multicolumn{2}{|c|}{3 ha } & \multicolumn{2}{|c|}{5 ha } & \multicolumn{2}{|c|}{1 ha } & \multicolumn{2}{|l|}{3 ha } & \multicolumn{2}{|c|}{5 ha } \\
\hline & $\mathrm{R} \$$ & $\%$ & $\mathrm{R} \$$ & $\%$ & $\mathrm{R} \$$ & $\%$ & $\mathrm{R} \$$ & $\%$ & $\mathrm{R} \$$ & $\%$ & $\mathrm{R} \$$ & $\%$ \\
\hline Preparo do solo & 455,00 & 3,01 & $1.365,00$ & 3,84 & $2.275,00$ & 4,07 & 455,00 & 2,71 & $1.365,00$ & 3,37 & $2.275,00$ & 3,56 \\
\hline Sementes & 60,00 & 0,40 & 180,00 & 0,51 & 300,00 & 0,54 & 60,00 & 0,36 & 180,00 & 0,44 & 300,00 & 0,47 \\
\hline Plantio & 362,50 & 2,40 & $1.087,50$ & 3,06 & $1.812,50$ & 3,43 & 362,50 & 2,16 & $1.087,50$ & 2,69 & $1.812,50$ & 2,83 \\
\hline Tratos culturais & 420,00 & 2,78 & $1.260,00$ & 3,55 & $2.100,00$ & 3,76 & 420,00 & 2,51 & $1.260,00$ & 3,11 & $2.100,00$ & 3,28 \\
\hline Irrigação & $5.086,42$ & 33,67 & $13.818,46$ & 38,90 & $21.928,51$ & 39,23 & $5.086,42$ & 30,35 & $13.818,46$ & 34,16 & $21.928,51$ & 34,27 \\
\hline Cercas & $1.943,23$ & 12,86 & $2.515,33$ & 7,08 & $3.187,21$ & 5,70 & $3.599,20$ & 21,47 & $7.446,00$ & 18,41 & $11.282,00$ & 17,63 \\
\hline Animais e C.M. ${ }^{1}$ & $6.777,93$ & 44,87 & $15.293,79$ & 43,06 & $24.289,65$ & 43,46 & 6.777,93 & 40,44 & $15.293,79$ & 37,81 & $24.289,65$ & 37,96 \\
\hline TOTAL & $15.105,08$ & 100,00 & $35.520,08$ & 100,00 & $55.892,87$ & 100,00 & $16.761,05$ & 100,00 & $40.450,75$ & 100,00 & $63.987,66$ & 100,00 \\
\hline
\end{tabular}

Tabela 2. Custo de implantação da área com pastagem de capim-tanzânia sob lotação rotativa para animais suplementados ao nível de 1,2 e 1,8\% PV, três tamanhos de área e divisão dos piquetes com cerca elétrica e de tela

\begin{tabular}{|c|c|c|c|c|c|c|c|c|c|c|c|c|}
\hline \multirow{4}{*}{$\begin{array}{l}\text { Serviços } \\
\text { e insumos }\end{array}$} & \multicolumn{12}{|c|}{ Animais suplementados ao nível de $1,2 \%$ PV } \\
\hline & \multicolumn{6}{|c|}{ Cerca elétrica } & \multicolumn{6}{|c|}{ Cerca de tela } \\
\hline & \multicolumn{2}{|c|}{1 ha } & \multicolumn{2}{|c|}{3 ha } & \multicolumn{2}{|c|}{5 ha } & \multicolumn{2}{|c|}{1 ha } & \multicolumn{2}{|c|}{3 ha } & \multicolumn{2}{|c|}{5 ha } \\
\hline & $\mathrm{R} \$$ & $\%$ & $\mathrm{R} \$$ & $\%$ & $\mathrm{R} \$$ & $\%$ & $\mathrm{R} \$$ & $\%$ & $\mathrm{R} \$$ & $\%$ & $\mathrm{R} \$$ & $\%$ \\
\hline Preparo do solo & 455,00 & 2,98 & $1.365,00$ & 3,79 & $2.275,00$ & 4,01 & 455,00 & 2,69 & $1.365,00$ & 3,34 & $2.275,00$ & 3,51 \\
\hline Sementes & 60,00 & 0,39 & 180,00 & 0,50 & 300,00 & 0,53 & 60,00 & 0,35 & 180,00 & 0,44 & 300,00 & 0,46 \\
\hline Plantio & 362,50 & 2,38 & $1.087,50$ & 3,02 & $1.812,50$ & 3,20 & 362,50 & 2,14 & $1.087,50$ & 2,66 & $1.812,50$ & 2,80 \\
\hline Tratos culturais & 420,00 & 2,75 & $1.260,00$ & 3,50 & $2.100,00$ & 3,71 & 420,00 & 2,48 & $1.260,00$ & 3,08 & $2.100,00$ & 3,24 \\
\hline Irrigação & $5.086,42$ & 33,33 & $13.818,46$ & 38,40 & 21.928,51 & 38,69 & $5.086,42$ & 30,07 & $13.818,46$ & 33,77 & 21.928,51 & 33,86 \\
\hline Cercas & $1.943,23$ & 12,73 & $2.515,33$ & 6,99 & $3.187,21$ & 5,62 & $3.599,20$ & 21,28 & $7.446,00$ & 18,20 & $11.282,00$ & 17,42 \\
\hline Animais e C.M. ${ }^{1}$ & 6.933,93 & 45,44 & $15.761,79$ & 43,80 & 25.069,65 & 44,24 & $6.933,93$ & 40,99 & $15.761,79$ & 38,52 & 25.069,65 & 38,71 \\
\hline \multirow[t]{2}{*}{ TOTAL } & $15.261,08$ & 100,00 & $35.988,08$ & 100,00 & $56.672,87$ & 100,00 & $16.917,05$ & 100,00 & $40.918,75$ & 100,00 & $64.767,66$ & 100,00 \\
\hline & \multicolumn{12}{|c|}{ Animais suplementados ao nível de $1,8 \%$ PV } \\
\hline Serviços & \multicolumn{2}{|c|}{1 ha } & \multicolumn{2}{|c|}{3 ha } & \multicolumn{2}{|c|}{5 ha } & \multicolumn{2}{|c|}{1 ha } & \multicolumn{2}{|c|}{3 ha } & \multicolumn{2}{|c|}{5 ha } \\
\hline e insumos & $\mathrm{R} \$$ & $\%$ & $\mathrm{R} \$$ & $\%$ & $\mathrm{R} \$$ & $\%$ & $\mathrm{R} \$$ & $\%$ & $\mathrm{R} \$$ & $\%$ & $\mathrm{R} \$$ & $\%$ \\
\hline Preparo do solo & 455,00 & 2,92 & $1.365,00$ & 3,69 & $2.275,00$ & 3,90 & 455,00 & 2,64 & $1.365,00$ & 3,26 & $2.275,00$ & 3,43 \\
\hline Sementes & 60,00 & 0,38 & 180,00 & 0,49 & 300,00 & 0,51 & 60,00 & 0,35 & 180,00 & 0,43 & 300,00 & 0,45 \\
\hline Plantio & 362,50 & 2,33 & $1.087,50$ & 2,94 & $1.812,50$ & 3,11 & 362,50 & 2,10 & $1.087,50$ & 2,60 & $1.812,50$ & 2,73 \\
\hline Tratos culturais & 420,00 & 2,69 & $1.260,00$ & 3,41 & $2.100,00$ & 3,60 & 420,00 & 2,44 & $1.260,00$ & 3,01 & $2.100,00$ & 3,16 \\
\hline Irrigação & $5.086,42$ & 32,63 & $13.818,46$ & 37,38 & 21.928,51 & 37,61 & $5.086,42$ & 29,50 & $13.818,46$ & 32,98 & $21.928,51$ & 33,03 \\
\hline Cercas & $1.943,23$ & 12,47 & $2.515,33$ & 6,80 & $3.187,21$ & 5,47 & $3.599,20$ & 20,87 & $7.446,00$ & 17,77 & $11.282,00$ & 16,99 \\
\hline Animais e C.M. ${ }^{1}$ & $7.260,20$ & 46,58 & $16.740,60$ & 45,29 & $26.701,00$ & 45,80 & $7.260,20$ & 42,10 & $16.740,60$ & 39,96 & $26.701,00$ & 40,21 \\
\hline TOTAL & $15.587,35$ & 100,00 & $36.966,89$ & 100,00 & $58.304,22$ & 100,00 & $17.243,32$ & 100,00 & $41.897,56$ & 100,00 & $66.399,01$ & 100,00 \\
\hline
\end{tabular}


Tabela 3. Custo anual de manutenção da área com pastagem de capim Tanzânia sob lotação para animais não suplementados e suplementados ao nível de $0,6 \% \mathrm{PV}$, três tamanhos de área e divisão dos piquetes com cerca elétrica e de tela

\begin{tabular}{|c|c|c|c|c|c|c|c|c|c|c|c|c|}
\hline \multirow{4}{*}{$\begin{array}{c}\text { Serviços } \\
\text { e insumos }\end{array}$} & \multicolumn{12}{|c|}{ Animais não suplementados } \\
\hline & \multicolumn{6}{|c|}{ Cerca elétrica } & \multicolumn{6}{|c|}{ Cerca de tela } \\
\hline & \multicolumn{2}{|c|}{1 ha } & \multicolumn{2}{|c|}{3 ha } & \multicolumn{2}{|l|}{5 ha } & \multicolumn{2}{|c|}{1 ha } & \multicolumn{2}{|c|}{3 ha } & \multicolumn{2}{|c|}{5 ha } \\
\hline & $\mathrm{R} \$$ & $\%$ & $\mathrm{R} \$$ & $\%$ & $\mathrm{R} \$$ & $\%$ & $\mathrm{R} \$$ & $\%$ & $\mathrm{R} \$$ & $\%$ & $\mathrm{R} \$$ & $\%$ \\
\hline Animais-20kg & $8.360,04$ & 44,74 & $25.080,12$ & 56,93 & $41.800,2$ & 60,21 & $8.360,04$ & 44,72 & $25.080,12$ & 56,91 & $41.800,2$ & 60,21 \\
\hline Trat. sanitário & 254,85 & 1,36 & 764,55 & 1,74 & $1.274,25$ & 1,84 & 254,85 & 1,36 & 764,55 & 1,73 & $1.274,25$ & 1,84 \\
\hline Adubação & $1.591,00$ & 8,51 & $4.773,00$ & 10,83 & $7.955,00$ & 11,46 & $1.591,00$ & 8,51 & $4.773,00$ & 10,83 & $7.955,00$ & 11,46 \\
\hline Limpeza & 300,00 & 1,61 & 900,00 & 2,04 & $1.500,00$ & 2,16 & 70,00 & 0,37 & 210,00 & 0,48 & 350,00 & 0,50 \\
\hline Energia & 404,66 & 2,17 & $1.213,97$ & 2,76 & $2.023,28$ & 2,91 & 404,66 & 2,16 & $1.213,97$ & 2,75 & $2.023,28$ & 2,91 \\
\hline Ração & 565,50 & 3,03 & $1.696,50$ & 3,85 & $2.827,50$ & 4,07 & 565,50 & 3,03 & $1.696,50$ & 3,85 & $2.827,50$ & 4,07 \\
\hline Deprec. sistemas ${ }^{1}$ & 329,79 & 1,76 & 837,56 & 1,90 & $1.336,97$ & 1,93 & 329,79 & 1,76 & 837,56 & 1,90 & $1.336,97$ & 1,93 \\
\hline Deprec. cercas & 103,72 & 0,56 & 118,84 & 0,27 & 138,95 & 0,20 & 197,01 & 1,05 & 393,88 & 0,89 & 590,12 & 0,85 \\
\hline Outros custos ${ }^{2}$ & $6.776,22$ & 36,26 & $8.671,60$ & 19,68 & $10.563,29$ & 15,21 & $6.921,12$ & 37,03 & $9.103,03$ & 20,66 & $11.271,58$ & 16,23 \\
\hline \multirow[t]{2}{*}{ TOTAL } & $18.685,78$ & 100,00 & $44.056,14$ & 100,00 & $69.419,441$ & 100,00 & $18.693,97$ & 100,00 & $44.072,61$ & 100,00 & $69.428,90$ & 100,00 \\
\hline & \multicolumn{12}{|c|}{ Animais suplementados ao nível de $0,6 \%$ PV } \\
\hline Serviços & \multicolumn{2}{|c|}{1 ha } & \multicolumn{2}{|l|}{3 ha } & \multicolumn{2}{|c|}{5 ha } & \multicolumn{2}{|c|}{1 ha } & \multicolumn{2}{|l|}{3 ha } & \multicolumn{2}{|c|}{5 ha } \\
\hline e insumos & $\mathrm{R} \$$ & $\%$ & $\mathrm{R} \$$ & $\%$ & $\mathrm{R} \$$ & $\%$ & $\mathrm{R} \$$ & $\%$ & $\mathrm{R} \$$ & $\%$ & $\mathrm{R} \$$ & $\%$ \\
\hline Animais-20kg & $10.926,24$ & 48,66 & $32.778,72$ & 59,21 & $54.631,2$ & 61,90 & $10.926,24$ & 48,64 & $32.778,72$ & 59,19 & $54.631,2$ & 61,89 \\
\hline Trat. sanitário & 283,85 & 1,26 & 851,55 & 1,54 & $1.419,25$ & 1,61 & 283,85 & 1,26 & 851,55 & 1,54 & $1.419,25$ & 1,61 \\
\hline Adubação & $1.591,00$ & 7,09 & $4.773,00$ & 8,62 & $7.955,00$ & 9,01 & $1.591,00$ & 7,08 & $4.773,00$ & 8,62 & $7.955,00$ & 9,01 \\
\hline Limpeza & 300,00 & 1,34 & 900,00 & 1,63 & $1.500,00$ & 1,70 & 70,00 & 0,31 & 210,00 & 0,38 & 350,00 & 0,40 \\
\hline Energia & 404,66 & 1,80 & $1.213,97$ & 2,19 & $2.023,28$ & 2,29 & 404,66 & 1,80 & $1.213,97$ & 2,19 & $2.023,28$ & 2,29 \\
\hline Ração & $1.733,30$ & 7,72 & $5.199,91$ & 9,39 & $8.666,51$ & 9,82 & $1.733,30$ & 7,72 & $5.199,91$ & 9,39 & $8.666,51$ & 9,82 \\
\hline Deprec. sistemas ${ }^{1}$ & 329,79 & 1,47 & 837,56 & 1,51 & $1.336,97$ & 1,51 & 329,79 & 1,47 & 837,56 & 1,51 & $1.336,97$ & 1,51 \\
\hline Deprec. cercas & 103,72 & 0,46 & 118,84 & 0,21 & 138,95 & 0,16 & 197,01 & 0,88 & 393,88 & 0,71 & 590,12 & 0,67 \\
\hline Outros custos ${ }^{2}$ & $6.781,69$ & 30,20 & $8.688,01$ & 15,70 & $10.590,63$ & 12,0 & $6.926,59$ & 30,83 & $9.119,44$ & 16,47 & $11.298,92$ & 12,80 \\
\hline TOTAL & $22.454,25$ & 100,00 & $55.361,55$ & 100,00 & $88.261,79$ & 100,00 & $22.462,44$ & 100,00 & $55.378,02$ & 100,00 & $88.271,25$ & 100,00 \\
\hline
\end{tabular}

Tabela 4. Custo anual de manutenção da área com pastagem de capim Tanzânia sob lotação para animais suplementados ao nível de 1,2 e 1,8\% PV, três tamanhos de área e divisão dos piquetes com cerca elétrica e de tela

\begin{tabular}{|c|c|c|c|c|c|c|c|c|c|c|c|c|}
\hline \multirow{4}{*}{$\begin{array}{l}\text { Serviços } \\
\text { e insumos }\end{array}$} & \multicolumn{12}{|c|}{ Animais suplementados ao nível de $1,2 \%$ PV } \\
\hline & \multicolumn{6}{|c|}{ Cerca elétrica } & \multicolumn{6}{|c|}{ Cerca de tela } \\
\hline & \multicolumn{2}{|c|}{1 ha } & \multicolumn{2}{|l|}{3 ha } & \multicolumn{2}{|l|}{5 ha } & \multicolumn{2}{|c|}{1 ha } & \multicolumn{2}{|c|}{3 ha } & \multicolumn{2}{|l|}{5 ha } \\
\hline & $\mathrm{R} \$$ & $\%$ & $\mathrm{R} \$$ & $\%$ & $\mathrm{R} \$$ & $\%$ & $\mathrm{R} \$$ & $\%$ & $\mathrm{R} \$$ & $\%$ & $\mathrm{R} \$$ & $\%$ \\
\hline Animais-20kg & $13.180,44$ & 49,50 & $39.541,32$ & 58,26 & $65.902,2$ & 60,39 & $13.180,44$ & 49,49 & $39.541,32$ & 58,24 & $65.902,2$ & 60,39 \\
\hline Trat. sanitário & 283,85 & 1,07 & 851,55 & 1,25 & $1.419,25$ & 1,30 & 283,85 & 1,07 & 851,55 & 1,25 & $1.419,25$ & 1,30 \\
\hline Adubação & $1.591,00$ & 5,98 & $4.773,00$ & 7,03 & $7.955,00$ & 7,29 & $1.591,00$ & 5,97 & $4.773,00$ & 7,03 & $7.955,00$ & 7,29 \\
\hline Limpeza & 300,00 & 1,13 & 900,00 & 1,33 & $1.500,00$ & 1,37 & 70,00 & 0,26 & 210,00 & 0,31 & 350,00 & 0,32 \\
\hline Energia & 404,66 & 1,52 & $1.213,97$ & 1,79 & $2.023,28$ & 1,85 & 404,66 & 1,52 & $1.213,97$ & 1,79 & $2.023,28$ & 1,85 \\
\hline Ração & 3.637,01 & 13,66 & $10.911,02$ & 16,07 & $18.185,03$ & 16,67 & 3.637,01 & 13,66 & $10.911,02$ & 16,07 & $18.185,03$ & 16,66 \\
\hline Deprec. sistemas ${ }^{1}$ & 329,79 & 1,24 & 837,56 & 1,23 & $1.336,97$ & 1,23 & 329,79 & 1,24 & 837,56 & 1,23 & $1.336,97$ & 1,23 \\
\hline Deprec & 103,72 & 0,39 & 118,84 & 0,18 & 138,95 & 0,13 & 197,01 & 0,74 & 393,88 & 0,58 & 590,12 & 0,54 \\
\hline Outros cus & $6.795,34$ & 25,52 & $8.728,96$ & 12,86 & $10.658,88$ & 9,76 & $6.940,24$ & 26,06 & $9.160,39$ & 15,31 & $11.367,17$ & 10,41 \\
\hline \multirow[t]{2}{*}{ TOTAL } & $26.625,81$ & 100,00 & $67.876,21$ & 100,00 & $109.119,56$ & 100,00 & $26.633,99$ & 100,00 & $67.892,68$ & 100,00 & $109.129,02$ & 100,00 \\
\hline & \multicolumn{12}{|c|}{ Animais suplementados ao nível de $1,8 \%$ PV } \\
\hline Serviços & \multicolumn{2}{|c|}{1 ha } & \multicolumn{2}{|l|}{3 ha } & 5 ha & & \multicolumn{2}{|c|}{1 ha } & \multicolumn{2}{|c|}{3 ha } & \multicolumn{2}{|l|}{5 ha } \\
\hline e insu & $\mathrm{R} \$$ & $\%$ & $\mathrm{R} \$$ & $\%$ & $\mathrm{R} \$$ & $\%$ & $\mathrm{R} \$$ & $\%$ & $\mathrm{R} \$$ & $\%$ & $\mathrm{R} \$$ & $\%$ \\
\hline Animais-20kg & $15.055,04$ & 48,87 & $45.165,12$ & 56,17 & $75.275,2$ & 57,90 & $15.055,04$ & 48,86 & $45.165,12$ & 56,16 & $75.275,2$ & 57,90 \\
\hline Trat. sanitário & 312,40 & 1,01 & 937,20 & 1,17 & $1.562,00$ & 1,20 & 312,40 & 1,01 & 937,20 & 1,17 & $1.562,00$ & 1,20 \\
\hline Adubação & $1.591,00$ & 5,17 & $4.773,00$ & 5,94 & $7.955,00$ & 6,12 & $1.591,00$ & 5,16 & $4.773,00$ & 5,93 & $7.955,00$ & 6,12 \\
\hline Limpeza & 300,00 & 0,97 & 900,00 & 1,12 & $1.500,00$ & 1,15 & 70,00 & 0,23 & 210,00 & 0,26 & 350,00 & 0,27 \\
\hline Energia & 404,66 & 1,31 & $1.213,97$ & 1,51 & $2.023,28$ & 1,56 & 404,66 & 1,31 & $1.213,97$ & 1,51 & $2.023,28$ & 1,56 \\
\hline Ração & $5.882,83$ & 19,10 & $17.648,48$ & 21,95 & $29.414,13$ & 22,63 & $5.882,83$ & 19,09 & $17.648,48$ & 21,94 & 29.414,13 & 22,62 \\
\hline Deprec. sistemas ${ }^{1}$ & 329,79 & 1,07 & 837,56 & 1,04 & $1.336,97$ & 1,03 & 329,79 & 1,07 & 837,56 & 1,04 & $1.336,97$ & 1,03 \\
\hline Deprec. cercas & 103,72 & 0,34 & 118,84 & 0,15 & 138,95 & 0,11 & 197,01 & 0,64 & 393,88 & 0,49 & 590,12 & 0,45 \\
\hline Outros custos $^{2}$ & $6.823,89$ & 22,15 & $8.814,60$ & 10,96 & $10.801,62$ & 8,30 & $6.968,79$ & 24,33 & $9.246,04$ & 11,50 & $11.509,91$ & 8,85 \\
\hline TOTAL & $30.803,32$ & 100,00 & $80.408,77$ & 100,00 & $130.007,16$ & 100,00 & $30.811,51$ & 100,00 & $80.425,24$ & 100,00 & $130.016,62$ & 100,00 \\
\hline
\end{tabular}


Quanto ao custo total de manutenção (Tabelas 3 e 4), os custos com a aquisição de animais foi o que mais onerou a atividade, ficando acima de $44 \%$, em todos os tratamentos para 1 ha, chegando a $61,90 \%$ no tratamento $1,2 \% \mathrm{PV}$, cerca elétrica e área de 5 ha. Pode-se observar ainda que o custo percentual desse item torna-se mais oneroso com a elevação do nível de suplementação em virtude do aumento da taxa de lotação, o que pode ser compensado pelo maior número de animais vendidos, aumentando as receitas. Os custos com a ração concentrada representaram não mais do que 22,63\% dos custos totais de manutenção do sistema simulado com maior nível de suplementação $(1,8 \% \quad \mathrm{PV})$. O sistema que utiliza cerca elétrica apresenta maior custo com limpeza em função da necessidade de retirada de plantas do pé da cerca visando evitar perda de corrente elétrica; no entanto, o sistema de cerca de tela apresenta maior custo com a depreciação, de forma que não se observa diferença significativa no custo de manutenção entre os sistemas.

A exploração de 1,0 ha mostrou-se economicamente inviável para qualquer nível de suplementação e tipo de cerca (Tabelas 5 a 12), onde pode ser observado que os custos totais foram maiores que as receitas totais auferidas, devendo-se ao fato de que os custos fixos foram mais elevados frente ao nível de produção obtido. À medida que se eleva o preço do produto, viabiliza-se a exploração de áreas a partir de 3,0 ha.

Observou-se que o preço médio de venda variando entre $R \$ 2,60$ e $2,80 / \mathrm{kg}$ PV não foi suficiente para cobrir os custos de produção de nenhum tratamento estudado, a taxa interna de retorno (TIR) foi inferior à taxa de juros de oportunidade do capital (8,75\%) para todos os tratamentos avaliados (Tabelas 5 a 12). Segundo CANZIANI (2005), quando o empreendimento apresenta margem líquida e bruta negativas, os custos não estão sendo cobertos pela receita gerada e se a situação for mantida assim, em médio ou longo prazo será levada à descapitalização progressiva, com inviabilidade da atividade.

O sistema de produção sem suplementação apresentou viabilidade econômica com o preço de venda a partir de R\$3,00/kg PV (Tabela 5). No entanto, com uma área de pastagem de 3,0 ha, o empreendimento só obteve retorno econômico com um preço de venda de $\mathrm{R} \$ 3,20 / \mathrm{kg} \mathrm{PV}$. Para a exploração de até 3,0 ha ao preço de $\mathrm{R} \$ 3,00 / \mathrm{kg}$
PV, o valor da taxa interna de retorno (TIR) é inferior ao da taxa de juros de oportunidade do capital (8,75\%). Considerando a exploração de 5,0 ha com cerca elétrica e preço de venda de R\$ 3,00/kg PV, para uma taxa de juros de 8,75\% o valor presente líquido (VPL) foi superior a zero (Tabela 5); portanto, esse sistema de produção permite um retorno superior ao custo de oportunidade do capital, ou seja, os benefícios satisfazem os custos de oportunidade de sujeitá-los à outras alternativas de aplicação financeira. Ainda nesse sistema de produção, a TIR mostrou-se maior (13\%) do que a taxa de juros de oportunidade do capital, tornando o investimento nessa atividade economicamente viável. A relação benefício/custo $(\mathrm{B} / \mathrm{C})$ desse sistema de produção demonstrou que o valor presente dos benefícios é praticamente igual aos custos. Considerando uma taxa de juros de $8,75 \%$ para cada unidade monetária de custo, o empreendimento gera apenas 1,022 de receita. Já com um preço de venda de $\mathrm{R} \$ 3,20 / \mathrm{kg} \mathrm{PV}$, observou-se uma B/C de 1,090.

Para o sistema que utilizou cerca de tela, somente foi verificada viabilidade econômica a partir dos preços de venda de $\mathrm{R} \$ 3,20 / \mathrm{kg} \mathrm{PV}$, para as áreas superiores a 5,0 ha, com B/C $>1,0$; VPL $>0$ e RL positiva (Tabela 6).

Quanto ao sistema de produção com suplementação ao nível de $0,6 \%$ PV e cerca elétrica, observou-se que à medida que se elevou o preço do produto, viabilizou-se a exploração de áreas a partir de 3,0 ha (Tabela 7).

Quando foi simulado o preço de venda variando entre $R \$ 2,60$ e 2,80/kg PV, a taxa interna de retorno (TIR) foi inferior à taxa de juros de oportunidade do capital $(8,75 \%)$ para todos os tamanhos de pastagem e tipos de contenção avaliados. Com uma área de pastagem de 5,0 ha, o sistema só obteve retorno econômico com um preço de venda de R\$3,00/kg PV. Para a exploração de até 3,0 ha ao preço de $\mathrm{R} \$ 3,00$, o valor da TIR (3,0\%) foi inferior ao da taxa de juros de oportunidade do capital. Considerando a exploração de 5,0 ha com cerca elétrica e preço de venda de R\$3,00/kg PV, para uma taxa de juros de 8,75\%, o valor presente líquido (VPL) foi superior a zero (Tabela 7); portanto, esse empreendimento permite um retorno suficiente para compensar os custos de oportunidade de submetê-lo à outras possibilidades de investimento. Ademais, a TIR mostrou-se maior (13\%) do que a taxa de juros de oportunidade do capital, tornando o investimento nessa atividade 
rentável. A relação benefício/custo (B/C) desse sistema de produção mostrou que o valor presente dos benefícios é praticamente igual aos custos, ou seja, para cada real aplicado no empreendimento, há acréscimo de apenas $\mathrm{R} \$ 1,020$ na receita. Já com um preço de venda de $\mathrm{R} \$ 3,20 / \mathrm{kg} \mathrm{PV}$, observou-se uma B/C de 1,088.

Para o sistema de produção com cerca de tela, somente foi verificada viabilidade econômica a partir dos preços de $\mathrm{R} \$ 3,20 / \mathrm{kg} \mathrm{PV}$, para as áreas de 3,0 e 5,0 ha, respectivamente (Tabela 8). O item que mais onerou a estrutura de custo de implantação foi a compra com o manejo dos animais cuja participação no custo total para exploração com cerca elétrica para 1,0; 3,0 e 5,0 ha foi de 44,87, 43,06 e 43,46\%, respectivamente (Tabela 1). Quanto ao sistema de cerca de tela, os custos com a compra e com o manejo dos animais foram de 40,44, 37,81 e 37,96\% para os sistemas de produção com 1,0; 3,0 e 5,0 ha, respectivamente. Os custos com a implantação do sistema de irrigação não apresentou mais que $40 \%$ para ambos os sistemas simulados. Quanto ao custo total de manutenção, os custos com a aquisição de animais (acima de 45\%) foram o que mais oneraram a atividade, enquanto que os custos com a ração concentrada representaram não mais do que $10 \%$ dos custos totais de manutenção dos sistemas simulados (Tabela 3).

Para o sistema com cerca de tela, de 3 ha com os animais suplementados ao nível de 0,6\% $\mathrm{PV}$, observou-se viabilidade somente com o preço de venda do produto acima de R 3,20/kg PV. Já para área de 5,0 ha, o sistema apresentou viável com o preço de venda a partir de $\mathrm{R} \$ 3,20 / \mathrm{kg} \mathrm{PV}$, com $\mathrm{B} / \mathrm{C}>1,0$; VPL $>0$ e RL positiva (Tabela 8).

Tabela 5. Índices econômicos para terminação de ovinos em pastagem de Panicum maximum cv. Tanzânia, irrigado sem suplementação concentrada em função de três tamanhos de área, cerca elétrica e diferentes preços pagos ao produtor

\begin{tabular}{|c|c|c|c|c|c|c|c|c|}
\hline Ano & $\begin{array}{c}\text { Preço } \\
\text { (R\$/kg PV) }\end{array}$ & $\begin{array}{c}\text { Investimento } \\
\text { (R\$) }\end{array}$ & $\begin{array}{c}\text { Custeio } \\
\text { (R\$/ano) }\end{array}$ & $\begin{array}{c}\mathrm{RB}^{1} \\
\text { (R\$/ano) }\end{array}$ & $\begin{array}{c}\mathrm{RL}^{2} \\
\text { (R\$/ano) }\end{array}$ & $\mathrm{B} / \mathrm{C}^{3}$ & $\begin{array}{c}\mathrm{VPL}^{4} \\
(\mathrm{R} \$)\end{array}$ & $\begin{array}{l}\mathrm{TIR}^{5} \\
(\%)\end{array}$ \\
\hline \multicolumn{9}{|c|}{ Sistema com cerca elétrica, área 1ha } \\
\hline 1 & \multirow{2}{*}{2,6} & $15.042,58$ & $9.112,00$ & $5.733,62$ & $-18.420,96$ & \multirow{2}{*}{0,649} & \multirow[b]{2}{*}{$-49.987,31$} & \multirow{2}{*}{$*$} \\
\hline $2-10$ & & - & $18.224,00$ & $13.359,32$ & $-4.864,68$ & & & \\
\hline 1 & \multirow{2}{*}{2,8} & $15.042,58$ & $9.112,00$ & $6.174,67$ & $-17.979,91$ & \multirow{2}{*}{0,699} & \multirow{2}{*}{$-42.878,03$} & \multirow{2}{*}{ * } \\
\hline $2-10$ & & - & $18.224,00$ & $14.386,96$ & $-3.837,04$ & & & \\
\hline 1 & \multirow{2}{*}{3,0} & $15.042,58$ & $9.112,00$ & $6.615,72$ & $-17.538,86$ & \multirow{2}{*}{0,749} & \multirow{2}{*}{$-35.768,74$} & \multirow{2}{*}{$*$} \\
\hline $2-10$ & & - & $18.224,00$ & $15.414,60$ & $-2.809,40$ & & & \\
\hline 1 & \multirow{2}{*}{3,2} & $15.042,58$ & $9.112,00$ & $7.056,77$ & $-17.097,81$ & \multirow{2}{*}{0,799} & \multirow{2}{*}{$-28.659,45$} & \multirow{2}{*}{ * } \\
\hline $2-10$ & & - & $18.224,00$ & $16.442,24$ & $-1.781,76$ & & & \\
\hline \multicolumn{9}{|c|}{ Sistema com cerca elétrica, área de 3 ha } \\
\hline 1 & \multirow{2}{*}{2,6} & $35.332,58$ & $21.239,24$ & $17.200,87$ & $-39.370,95$ & \multirow{2}{*}{0,835} & \multirow{2}{*}{$-54.947,66$} & \multirow{2}{*}{ * } \\
\hline $2-10$ & & - & $42.478,48$ & $40.077,96$ & $-2.400,52$ & & & \\
\hline 1 & \multirow{2}{*}{2,8} & $35.332,58$ & $21.239,24$ & $18.524,02$ & $-38.047,80$ & \multirow{2}{*}{0,899} & \multirow{2}{*}{$-33.619,79$} & \multirow{2}{*}{$-23 \%$} \\
\hline $2-10$ & & - & $42.478,48$ & $43.160,88$ & 682,40 & & & \\
\hline 1 & \multirow[b]{2}{*}{3,0} & $35.332,58$ & $21.239,24$ & $19.847,16$ & $-36.724,66$ & \multirow{2}{*}{0,963} & \multirow[b]{2}{*}{$-12.291,93$} & \multirow[b]{2}{*}{$0 \%$} \\
\hline $2-10$ & & - & $42.478,48$ & $46.243,80$ & $3.765,32$ & & & \\
\hline 1 & \multirow{2}{*}{3,2} & $35.332,58$ & $21.239,24$ & $21.170,30$ & $-35.401,52$ & & & \\
\hline $2-10$ & & - & $42.478,48$ & 49.326,72 & $6.848,24$ & 1,027 & $9.035,92$ & $14 \%$ \\
\hline & & & Sistema c & rca elétrica, & de 5 ha & & & \\
\hline 1 & 26 & $55.580,37$ & $33.365,45$ & $28.668,12$ & $-60.277,70$ & 0885 & 5985132 & $-45 \%$ \\
\hline $2-10$ & 2,0 & - & $66.730,89$ & $66.796,60$ & 65,71 & 0,885 & $-59.851,32$ & $-45 \%$ \\
\hline 1 & 28 & $55.580,37$ & $33.365,45$ & $30.873,36$ & $-58.072,46$ & & & \\
\hline $2-10$ & 2,0 & - & $66.730,89$ & $71.934,80$ & $5.203,91$ & 0,953 & $-24.304,89$ & $-2 \%$ \\
\hline 1 & 30 & $55.580,37$ & $33.365,45$ & $33.078,60$ & $-55.867,22$ & 1027 & 1124155 & $13 \%$ \\
\hline $2-10$ & 3,0 & - & $66.730,89$ & $77.073,00$ & $10.342,11$ & $1,0<2$ & $11.241,55$ & $13 \%$ \\
\hline 1 & & $55.580,37$ & $33.365,45$ & $35.283,84$ & $-53.661,98$ & 1,090 & 46.787,98 & $26 \%$ \\
\hline $2-10$ & 3,2 & - & $66.730,89$ & $82.211,20$ & $15.480,31$ & & & \\
\hline
\end{tabular}


Tabela 6. Índices econômicos para terminação de ovinos em pastagem de Panicum maximum cv. Tanzânia, irrigado sem suplementação concentrada em função de três tamanhos de área, cerca de tela e diferentes preços pagos ao produtor

\begin{tabular}{|c|c|c|c|c|c|c|c|c|}
\hline Ano & $\begin{array}{c}\text { Preço } \\
(\mathrm{R} \$ / \mathrm{kg} P V)\end{array}$ & $\begin{array}{c}\text { Investimento } \\
(\mathrm{R} \$)\end{array}$ & $\begin{array}{l}\text { Custeio } \\
\text { (R\$/ano) }\end{array}$ & $\begin{array}{c}\mathrm{RB}^{\mathrm{I}} \\
\text { (R\$/ano) }\end{array}$ & $\begin{array}{c}\mathrm{RL}^{2} \\
\text { (R\$/ano) }\end{array}$ & $\mathrm{B} / \mathrm{C}^{3}$ & $\begin{array}{l}\mathrm{VPL}^{4} \\
\text { (R\$) }\end{array}$ & $\begin{array}{l}\mathrm{TIR}^{5} \\
(\%)\end{array}$ \\
\hline \multicolumn{9}{|c|}{ Sistema com cerca de tela, área de 1 ha } \\
\hline $\begin{array}{c}1 \\
2-10\end{array}$ & 2,6 & $\begin{array}{c}16.698,55 \\
-\end{array}$ & $\begin{array}{c}9.277,74 \\
18.555,48\end{array}$ & $\begin{array}{c}5.733,62 \\
13.359,32\end{array}$ & $\begin{array}{c}-20.242,67 \\
-5.196,16\end{array}$ & 0,631 & $-53.959,97$ & $*$ \\
\hline $\begin{array}{c}1 \\
2-10\end{array}$ & 2,8 & $\begin{array}{c}16.698,55 \\
-\end{array}$ & $\begin{array}{c}9.277,74 \\
18.555,48 \\
\end{array}$ & $\begin{array}{c}6.174,67 \\
14.386,96 \\
\end{array}$ & $\begin{array}{l}-19.801,62 \\
-4.168,52 \\
\end{array}$ & 0,680 & $-46.850,68$ & * \\
\hline $\begin{array}{c}1 \\
2-10\end{array}$ & 3,0 & $\begin{array}{c}16.698,55 \\
-\end{array}$ & $\begin{array}{c}9.277,74 \\
18.555,48\end{array}$ & $\begin{array}{c}6.615,72 \\
15.414,60\end{array}$ & $\begin{array}{c}-19.360,57 \\
-3.140,88\end{array}$ & 0,729 & $-39.741,40$ & * \\
\hline $\begin{array}{c}1 \\
2-10\end{array}$ & 3,2 & $\begin{array}{c}16.698,55 \\
-\end{array}$ & $\begin{array}{c}9.277,74 \\
18.555,48\end{array}$ & $\begin{array}{c}7.056,77 \\
16.442,24\end{array}$ & $\begin{array}{c}-18.919,52 \\
-2.113,24\end{array}$ & 0,777 & $-32.632,11$ & * \\
\hline \multicolumn{9}{|c|}{ Sistema com cerca de tela, área de 3 ha } \\
\hline $\begin{array}{c}1 \\
2-10\end{array}$ & 2,6 & $\begin{array}{c}40.263,25 \\
-\end{array}$ & $\begin{array}{l}21.730,00 \\
43.459,99\end{array}$ & $\begin{array}{l}17.200,87 \\
40.077,96\end{array}$ & $\begin{array}{c}-44.792,38 \\
-3.382,03\end{array}$ & 0,806 & $-66.738,01$ & * \\
\hline $\begin{array}{c}1 \\
2-10\end{array}$ & 2,8 & $\begin{array}{c}40.263,25 \\
-\end{array}$ & $\begin{array}{l}21.730,00 \\
43.459,99\end{array}$ & $\begin{array}{l}18.524,02 \\
43.160,88\end{array}$ & $\begin{array}{c}-43.469,23 \\
-299,11\end{array}$ & 0,868 & $-45.410,14$ & * \\
\hline $\begin{array}{c}1 \\
2-10\end{array}$ & 3,0 & $\begin{array}{c}40.263,25 \\
-\end{array}$ & $\begin{array}{l}21.730,00 \\
43.459,99\end{array}$ & $\begin{array}{l}19.847,16 \\
46.243,80\end{array}$ & $\begin{array}{c}-42.146,09 \\
2.783,81\end{array}$ & 0,930 & $-24.082,29$ & $-7 \%$ \\
\hline $\begin{array}{c}1 \\
2-10\end{array}$ & 3,2 & $\begin{array}{c}40.263,25 \\
-\end{array}$ & $\begin{array}{l}21.730,00 \\
43.459,99\end{array}$ & $\begin{array}{l}21.170,30 \\
49.326,72\end{array}$ & $\begin{array}{c}-40.822,95 \\
5.866,73\end{array}$ & 0,992 & $-2.754,43$ & $7 \%$ \\
\hline \multicolumn{9}{|c|}{ Sistema com cerca de tela, área de 5 ha } \\
\hline $\begin{array}{c}1 \\
2-10\end{array}$ & 2,6 & $\begin{array}{c}63.675,16 \\
-\end{array}$ & $\begin{array}{l}34.170,76 \\
68.341,51\end{array}$ & $\begin{array}{l}28.668,12 \\
66.796,60\end{array}$ & $\begin{array}{c}-69.177,80 \\
-1.544,91\end{array}$ & 0,854 & $-79.202,56$ & * \\
\hline $\begin{array}{c}1 \\
2-10\end{array}$ & 2,8 & $\begin{array}{c}63.675,16 \\
-\end{array}$ & $\begin{array}{l}34.170,76 \\
68.341,51\end{array}$ & $\begin{array}{l}30.873,36 \\
71.934,80\end{array}$ & $\begin{array}{c}-66.972,56 \\
3.593,29\end{array}$ & 0,919 & $-43.656,13$ & $-10 \%$ \\
\hline $\begin{array}{c}1 \\
2-10\end{array}$ & 3,0 & $\begin{array}{c}63.675,16 \\
-\end{array}$ & $\begin{array}{l}34.170,76 \\
68.341,51\end{array}$ & $\begin{array}{l}33.078,60 \\
77.073,00\end{array}$ & $\begin{array}{c}-64.767,32 \\
8.731,49\end{array}$ & 0,985 & $-8.109,70$ & $6 \%$ \\
\hline $\begin{array}{c}1 \\
2-10\end{array}$ & 3,2 & $\begin{array}{c}\text { 63.675,16 } \\
-\end{array}$ & $\begin{array}{l}34.170,76 \\
68.341,51\end{array}$ & $\begin{array}{l}35.283,84 \\
82.211,20\end{array}$ & $\begin{array}{c}-62.562,08 \\
13.869,69\end{array}$ & 1,051 & $27.436,74$ & $18 \%$ \\
\hline
\end{tabular}

${ }^{1}$ Receita bruta; ${ }^{2}$ Receita líquida; ${ }^{3}$ Relação benefício/custo; ${ }^{4}$ Valor presente líquido; ${ }^{5}$ Taxa interna de retorno.

* Não foi possível encontrar uma solução.

Tabela 7. Índices econômicos para terminação de ovinos em pastagem de cv. Tanzânia, irrigado com suplementação concentrada ao nível de 0,6\% PV em função de três tamanhos de área, cerca elétrica e diferentes preços pagos ao produtor

\begin{tabular}{|c|c|c|c|c|c|c|c|c|}
\hline Ano & $\begin{array}{c}\text { Preço } \\
\mathrm{R} \$ / \mathrm{kg} \mathrm{PV)}\end{array}$ & $\begin{array}{l}\text { Investimento } \\
\text { (R\$) }\end{array}$ & $\begin{array}{l}\text { Custeio } \\
\text { (R\$/ano) }\end{array}$ & $\begin{array}{c}\mathrm{RB}^{\mathrm{I}} \\
\text { (R\$/ano) }\end{array}$ & $\begin{array}{c}\mathrm{RL}^{2} \\
\text { (R\$/ano) }\end{array}$ & $\mathrm{B} / \mathrm{C}^{3}$ & $\begin{array}{l}\mathrm{VPL}^{4} \\
(\mathrm{R} \$)\end{array}$ & $\begin{array}{l}\mathrm{TIR}^{5} \\
(\%)\end{array}$ \\
\hline \multicolumn{9}{|c|}{ Sistema com cerca elétrica, área 1ha } \\
\hline $\begin{array}{c}1 \\
2-10\end{array}$ & 2,6 & $\begin{array}{c}15.105,08 \\
-\end{array}$ & $\begin{array}{l}11.278,99 \\
22.557,97\end{array}$ & $\begin{array}{c}5.660,20 \\
17.486,56\end{array}$ & $\begin{array}{l}20.723,87 \\
-5.071,41\end{array}$ & 0,690 & $-53.631,68$ & * \\
\hline $\begin{array}{c}1 \\
2-10\end{array}$ & 2,8 & $\begin{array}{c}15.105,08 \\
-\end{array}$ & $\begin{array}{l}11.278,99 \\
22.557,97\end{array}$ & $\begin{array}{c}6.095,60 \\
18.831,68\end{array}$ & $\begin{array}{l}-20.288,47 \\
-3.726,29\end{array}$ & 0,743 & $-44.467,95$ & * \\
\hline $\begin{array}{c}1 \\
2-10\end{array}$ & 3,0 & $\begin{array}{c}15.105,08 \\
-\end{array}$ & $\begin{array}{l}11.278,99 \\
22.557,97\end{array}$ & $\begin{array}{c}6.531,00 \\
20.176,80\end{array}$ & $\begin{array}{l}-19.853,07 \\
-2.381,17\end{array}$ & 0,796 & $-35.304,22$ & * \\
\hline $\begin{array}{c}1 \\
2-10\end{array}$ & 3,2 & $\begin{array}{c}15.105,08 \\
-\end{array}$ & $\begin{array}{l}11.278,99 \\
22.557,97\end{array}$ & $\begin{array}{c}6.966,40 \\
21.521,92\end{array}$ & $\begin{array}{l}-19.417,67 \\
-1.036,05\end{array}$ & 0.849 & $-26.140,49$ & * \\
\hline \multicolumn{9}{|c|}{ Sistema com cerca elétrica, área de 3 ha } \\
\hline $\begin{array}{c}1 \\
2-10\end{array}$ & 2,6 & $\begin{array}{c}35.520,08 \\
-\end{array}$ & $\begin{array}{l}27.740,20 \\
55.480,39\end{array}$ & $\begin{array}{l}16.980,60 \\
52.459,68\end{array}$ & $\begin{array}{l}-46.279,68 \\
-3.020,71\end{array}$ & 0,844 & $-65.880,75$ & * \\
\hline $\begin{array}{c}1 \\
2-10\end{array}$ & 2,8 & $\begin{array}{c}35.520,08 \\
-\end{array}$ & $\begin{array}{l}27.740,20 \\
55.480,39\end{array}$ & $\begin{array}{l}18.286,80 \\
56.495,04\end{array}$ & $\begin{array}{c}-44.973,48 \\
1.014,65\end{array}$ & 0,909 & $-38.389,56$ & $-21 \%$ \\
\hline $\begin{array}{c}1 \\
2-10\end{array}$ & 3,0 & $\begin{array}{c}35.520,08 \\
-\end{array}$ & $\begin{array}{l}27.740,20 \\
55.480,39\end{array}$ & $\begin{array}{l}19.593,00 \\
60.530,40\end{array}$ & $\begin{array}{c}-43.667,28 \\
5.050,01\end{array}$ & 0,974 & $-10.898,37$ & $3 \%$ \\
\hline $\begin{array}{c}1 \\
2-10\end{array}$ & 3,2 & $\begin{array}{c}35.520,08 \\
-\end{array}$ & $\begin{array}{l}27.740,20 \\
55.480,39\end{array}$ & $\begin{array}{l}20.899,20 \\
64.565,76\end{array}$ & $\begin{array}{c}-42.361,08 \\
9.085,37\end{array}$ & 1,039 & $16.592,82$ & $17 \%$ \\
\hline \multicolumn{9}{|c|}{ Sistema com cerca elétrica, área de 5 ha } \\
\hline $\begin{array}{c}1 \\
2-10\end{array}$ & 2,6 & $\begin{array}{c}55.892,87 \\
-\end{array}$ & $\begin{array}{l}44.200,38 \\
88.400,75\end{array}$ & $\begin{array}{l}28.301,00 \\
87.437,80\end{array}$ & $\begin{array}{c}-71.792,25 \\
-967,95\end{array}$ & 0,884 & $-78.073,15$ & * \\
\hline $\begin{array}{c}1 \\
2-10\end{array}$ & 2,8 & $\begin{array}{c}55.892,87 \\
-\end{array}$ & $\begin{array}{l}44.200,38 \\
88.400,75\end{array}$ & $\begin{array}{l}30.478,00 \\
94.158,40\end{array}$ & $\begin{array}{l}-69.615,25 \\
5.757,65\end{array}$ & 0,952 & $-32.254,50$ & $-3 \%$ \\
\hline $\begin{array}{c}1 \\
2-10\end{array}$ & 3,0 & $\begin{array}{c}55.892,87 \\
-\end{array}$ & $\begin{array}{l}44.200,38 \\
88.400,75\end{array}$ & $\begin{array}{c}32.655,00 \\
100.884,00\end{array}$ & $\begin{array}{c}-67.438,25 \\
12.483,25\end{array}$ & 1,020 & $13.564,16$ & $13 \%$ \\
\hline $\begin{array}{c}1 \\
2-10\end{array}$ & 3,2 & $\begin{array}{c}55.892,87 \\
-\end{array}$ & $\begin{array}{l}44.200,38 \\
88.400,75\end{array}$ & $\begin{array}{c}34.832,00 \\
107.609,60\end{array}$ & $\begin{array}{c}-65.261,25 \\
19.208,85\end{array}$ & 1,088 & $59.382,81$ & $27 \%$ \\
\hline
\end{tabular}

${ }^{1}$ Receita bruta; ${ }^{2}$ Receita líquida; ${ }^{3}$ Relação benefício/custo; ${ }^{4}$ Valor presente líquido; ${ }^{5}$ Taxa interna de retorno.

* Não foi possível encontrar uma solução. 
Tabela 8. Índices econômicos para terminação de ovinos em pastagem de cv. Tanzânia, irrigado com suplementação concentrada ao nível de $0,6 \%$ PV em função de três tamanhos de área, cerca de tela e diferentes preços pagos ao produtor

\begin{tabular}{|c|c|c|c|c|c|c|c|c|}
\hline Ano & $\begin{array}{c}\text { Preço } \\
(\mathrm{R} \$ / \mathrm{kg} \mathrm{PV})\end{array}$ & $\begin{array}{c}\text { Investimento } \\
(\mathrm{R} \$)\end{array}$ & $\begin{array}{c}\text { Custeio } \\
\text { (R\$/ano) }\end{array}$ & $\begin{array}{c}\mathrm{RB}^{1} \\
\text { (R\$/ano) }\end{array}$ & $\begin{array}{c}\mathrm{RL}^{2} \\
\text { (R\$/ano) }\end{array}$ & $\mathrm{B} / \mathrm{C}^{3}$ & $\begin{array}{l}\mathrm{VPL}^{4} \\
(\mathrm{R} \$)\end{array}$ & $\begin{array}{l}\mathrm{TIR}^{5} \\
(\%)\end{array}$ \\
\hline \multicolumn{9}{|c|}{ Sistema com cerca de tela, área de 1 ha } \\
\hline $\begin{array}{c}1 \\
2-10\end{array}$ & 2,6 & $\begin{array}{c}16.761,05 \\
-\end{array}$ & $\begin{array}{l}11.444,73 \\
22.889,45\end{array}$ & $\begin{array}{c}5.660,20 \\
17.486,56\end{array}$ & $\begin{array}{c}-22.545,58 \\
-5.402,89\end{array}$ & 0,674 & $-57.604,34$ & $*$ \\
\hline $\begin{array}{c}1 \\
2-10\end{array}$ & 2,8 & $\begin{array}{c}16.761,05 \\
-\end{array}$ & $\begin{array}{l}11.444,73 \\
22.889,45 \\
\end{array}$ & $\begin{array}{c}6.095,60 \\
18.831,68 \\
\end{array}$ & $\begin{array}{c}-22.110,18 \\
-4.057,77 \\
\end{array}$ & 0,726 & $-48.440,61$ & $*$ \\
\hline $\begin{array}{c}1 \\
2-10 \\
\end{array}$ & 3,0 & $\begin{array}{c}16.761,05 \\
-\end{array}$ & $\begin{array}{l}11.444,73 \\
22.889,45 \\
\end{array}$ & $\begin{array}{c}6.531,00 \\
20.176,80 \\
\end{array}$ & $\begin{array}{l}-21.674,78 \\
-2.712,65 \\
\end{array}$ & 0,778 & $-39.276,88$ & * \\
\hline $\begin{array}{c}1 \\
2-10 \\
\end{array}$ & 3,2 & $\begin{array}{c}16.761,05 \\
-\end{array}$ & $\begin{array}{l}11.444,73 \\
22.889,45 \\
\end{array}$ & $\begin{array}{c}6.966,40 \\
21.521,92 \\
\end{array}$ & $\begin{array}{c}-21.239,38 \\
-1.367,53 \\
\end{array}$ & 0,830 & $-30.113,15$ & $*$ \\
\hline \multicolumn{9}{|c|}{ Sistema com cerca de tela, área de 3 ha } \\
\hline $\begin{array}{c}1 \\
2-10 \\
\end{array}$ & 2,6 & $\begin{array}{c}40.450,75 \\
- \\
\end{array}$ & $\begin{array}{l}28.230,96 \\
56.461,91 \\
\end{array}$ & $\begin{array}{l}16.980,60 \\
52.459,68 \\
\end{array}$ & $\begin{array}{c}-51.701,11 \\
-4.002,23 \\
\end{array}$ & 0,822 & $-77.671,11$ & * \\
\hline $\begin{array}{c}1 \\
2-10 \\
\end{array}$ & 2,8 & $\begin{array}{c}40.450,75 \\
- \\
\end{array}$ & $\begin{array}{l}28.230,96 \\
56.461,91 \\
\end{array}$ & $\begin{array}{l}18.286,80 \\
56.495,04 \\
\end{array}$ & $\begin{array}{c}-50.394,91 \\
33,13 \\
\end{array}$ & 0,885 & $-50.179,92$ & $-48 \%$ \\
\hline $\begin{array}{c}1 \\
2-10 \\
\end{array}$ & 3,0 & $\begin{array}{c}40.450,75 \\
- \\
\end{array}$ & $\begin{array}{l}28.230,96 \\
56.461,91 \\
\end{array}$ & $\begin{array}{l}19.593,00 \\
60.530,40 \\
\end{array}$ & $\begin{array}{c}-49.088,71 \\
4.068,49 \\
\end{array}$ & 0,948 & $-22.688,72$ & $3 \%$ \\
\hline $\begin{array}{c}1 \\
2-10\end{array}$ & 3,2 & $\begin{array}{c}40.450,75 \\
-\end{array}$ & $\begin{array}{l}28.230,96 \\
56.461,91 \\
\end{array}$ & $\begin{array}{l}20.899,20 \\
64.565,76 \\
\end{array}$ & $\begin{array}{c}-47.782,51 \\
8.103,85 \\
\end{array}$ & 1,011 & $4.802,47$ & $11 \%$ \\
\hline \multicolumn{9}{|c|}{ Sistema com cerca de tela, área de 5 ha } \\
\hline $\begin{array}{c}1 \\
2-10 \\
\end{array}$ & 2,6 & $\begin{array}{c}63.987,66 \\
- \\
\end{array}$ & $\begin{array}{l}45.005,69 \\
90.011,37 \\
\end{array}$ & $\begin{array}{l}28.301,00 \\
87.432,80 \\
\end{array}$ & $\begin{array}{c}-80.692,35 \\
-2.578,57 \\
\end{array}$ & 0,859 & $-97.424,39$ & * \\
\hline $\begin{array}{c}1 \\
2-10 \\
\end{array}$ & 2,8 & $\begin{array}{c}63.987,66 \\
- \\
\end{array}$ & $\begin{array}{l}45.005,69 \\
90.011,37 \\
\end{array}$ & $\begin{array}{l}30.478,00 \\
94.158,40 \\
\end{array}$ & $\begin{array}{c}-78.515,35 \\
4.147,03 \\
\end{array}$ & 0,926 & $-51.605,74$ & $-10 \%$ \\
\hline $\begin{array}{c}1 \\
2-10 \\
\end{array}$ & 3,0 & $\begin{array}{c}63.987,66 \\
- \\
\end{array}$ & $\begin{array}{l}45.005,69 \\
90.011,37 \\
\end{array}$ & $\begin{array}{c}32.655,00 \\
100.884,00 \\
\end{array}$ & $\begin{array}{c}-76.338,35 \\
10.872,63 \\
\end{array}$ & 0,992 & $-5.787,09$ & $7 \%$ \\
\hline $\begin{array}{c}1 \\
2-10 \\
\end{array}$ & 3,2 & $\begin{array}{c}63.987,66 \\
-\end{array}$ & $\begin{array}{l}45.005,69 \\
90.011,37 \\
\end{array}$ & $\begin{array}{c}34.832,00 \\
107.609,60 \\
\end{array}$ & $\begin{array}{c}-74.161,35 \\
17.598,23 \\
\end{array}$ & 1,058 & $40.031,56$ & $20 \%$ \\
\hline
\end{tabular}

${ }^{1}$ Receita bruta; ${ }^{2}$ Receita líquida; ${ }^{3}$ Relação benefício/custo; ${ }^{4}$ Valor presente líquido; ${ }^{5}$ Taxa interna de retorno.

* Não foi possível encontrar uma solução.

Tabela 9. Índices econômicos para terminação de ovinos em pastagem de Panicum maximum cv. Tanzânia, irrigado com suplementação concentrada ao nível de 1,2\% PV em função de três tamanhos de área, cerca elétrica e diferentes preços pagos ao produtor

\begin{tabular}{|c|c|c|c|c|c|c|c|c|}
\hline Ano & $\begin{array}{c}\text { Preço } \\
\mathrm{R} \$ / \mathrm{kg} \text { PV) } \\
\end{array}$ & $\begin{array}{l}\text { Investimento } \\
\text { (R\$) }\end{array}$ & $\begin{array}{l}\text { Custeio } \\
\text { (R\$/ano) } \\
\end{array}$ & $\begin{array}{c}\mathrm{RB}^{1} \\
\text { (R\$/ano) } \\
\end{array}$ & $\begin{array}{c}\mathrm{RL}^{2} \\
\text { (R\$/ano) } \\
\end{array}$ & $\mathrm{B} / \mathrm{C}^{3}$ & $\begin{array}{l}\mathrm{VPL}^{4} \\
\text { (R\$) }\end{array}$ & $\begin{array}{l}\mathrm{TIR}^{5} \\
(\%)\end{array}$ \\
\hline \multicolumn{9}{|c|}{ Sistema com cerca elétrica, área 1ha } \\
\hline 1 & 2,6 & $15.261,08$ & $13.364,76$ & $5.907,20$ & $-22.718,64$ & 0706 & $-59.338,83$ & * \\
\hline$\frac{2-10}{1}$ & 28 & $\frac{-}{1526108}$ & $\begin{array}{l}26.729,52 \\
13.36476\end{array}$ & $\frac{21.086,00}{6.361 .00}$ & $\begin{array}{c}-5.643,52 \\
-22.264,24\end{array}$ & 0761 & -4835945 & * \\
\hline $2-10$ & & $\begin{array}{c}10.201,00 \\
-\end{array}$ & $26.729,52$ & $22.708,00$ & $-4.021,52$ & & & \\
\hline 1 & 3,0 & $15.261,08$ & $13.364,76$ & $6.816,00$ & $-21.809,84$ & 0,815 & $-37.380,08$ & * \\
\hline $2-10$ & & - & $26.729,52$ & $24.330,00$ & $-2.399,52$ & & & \\
\hline 1 & 3,2 & $15.261,08$ & $13.364,76$ & $7.270,40$ & $-21.355,44$ & 0,869 & $-26.400,71$ & * \\
\hline $2-10$ & & - & $26.729,52$ & $25.952,00$ & $-777,52$ & & & \\
\hline \multicolumn{9}{|c|}{ Sistema com cerca elétrica, área de 3 ha } \\
\hline 1 & 2,6 & $35.988,08$ & $33.997,53$ & $17.721,60$ & $-52.264,01$ & 0,838 & $-83.002,22$ & $*$ \\
\hline $2-10$ & & - & $67.995,05$ & $63.258,00$ & $-4.737,05$ & & & \\
\hline 1 & 2,8 & $35.988,08$ & $33.997,53$ & $19.084,80$ & $-50.900,81$ & 0,902 & $-50.064,10$ & $-40 \%$ \\
\hline $2-10$ & & - & $67.995,05$ & $68.124,00$ & 128,95 & & & \\
\hline 1 & 3,0 & $35.988,08$ & $33.997,53$ & $20.448,00$ & $-49.537,61$ & 0,967 & $-17.125,98$ & $0 \%$ \\
\hline $2-10$ & & - & $67.995,05$ & $72.990,00$ & $4.994,95$ & & & \\
\hline 1 & 3,2 & $35.988,08$ & $33.997,53$ & $21.811,20$ & $-48.174,41$ & 1,031 & $15.812,14$ & $16 \%$ \\
\hline $2-10$ & & - & $67.995,05$ & $77.856,00$ & $9.860,95$ & & & \\
\hline \multicolumn{9}{|c|}{ Sistema com cerca elétrica, área de 5 ha } \\
\hline 1 & 2,6 & $56.672,87$ & $54.629,26$ & $29.536,00$ & $-81.766,13$ & 0,870 & $-106.608,92$ & $*$ \\
\hline $2-10$ & & - & $109.258,51$ & $105.430,00$ & $-3.828,51$ & & & \\
\hline 1 & 2,8 & $56.672,87$ & $54.629,26$ & $31.808,00$ & $-79.494,13$ & 0,937 & $-51.712,05$ & $-10 \%$ \\
\hline $2-10$ & & - & $109.258,51$ & $113.540,00$ & $4.281,49$ & & & \\
\hline 1 & 3,0 & $56.672,87$ & $54.629,26$ & $34.080,00$ & $-77.222,13$ & 1,004 & $3.184,81$ & $10 \%$ \\
\hline $2-10$ & & - & $109.258,51$ & $121.650,00$ & $12.391,49$ & & & \\
\hline 1 & 3,2 & $56.672,87$ & $54.629,26$ & $36.352,00$ & $-74.950,13$ & 1,071 & $58.081,68$ & $24 \%$ \\
\hline $2-10$ & & - & $109.258,51$ & $129.760,00$ & $20.501,49$ & & & \\
\hline
\end{tabular}


O sistema com o nível de suplementação de 1,2\% PV apresentou melhores resultados em relação ao status fisiológico do animal, o qual foi promovido pela melhoria na digestibilidade da fibra, aumentando a taxa de passagem ruminal (FARIA \& HUBER, 1984) e, consequentemente, maior consumo da forragem, caracterizando efeito aditivo; nesse nível de suplementação, a sincronização entre os níveis de proteína e de energia no rúmen propiciou condições adequadas para a fermentação microbiana, promovendo melhores condições de digestão e de aproveitamento do alimento. Ademais, observouse que à medida que se elevou o preço do produto, viabilizou-se o empreendimento de áreas a partir de 3,0 ha (Tabelas 9 e 10).

Com uma área de pastagem de 5,0 ha dotada com cerca elétrica, o sistema só obteve retorno econômico com um preço de venda acima de R\$ 3,00/kg PV. Considerando a exploração do mesmo sistema, mas com preço de venda de $\mathrm{R} \$ 3,20 / \mathrm{kg}$ $\mathrm{PV}$, para uma taxa de juros de $8,75 \%$ o valor presente líquido (VPL) foi superior a zero (Tabela 9); portanto, esse sistema de produção possibilita um lucro superior ao custo de oportunidade do capital, ou seja, as vantagens desse empreendimento foram suficientes para pagar os custos de oportunidade de sujeitá-lo à outras alternativas de investimento. Além disso, a TIR mostrou-se maior (24\%) do que a taxa de juros de oportunidade do capital, tornando o investimento economicamente viável. A relação benefício/custo $(\mathrm{B} / \mathrm{C})$ desse sistema de produção mostrou que o valor presente dos benefícios é superior aos dos custos, ou seja, para cada real aplicado no empreendimento, há acréscimo de $\mathrm{R} \$ 1,071$ na receita.

Para o sistema de produção com cerca de tela, somente foi verificada viabilidade econômica com preços de venda a partir R $\$ 3,20 / \mathrm{kg} P V$, para as áreas de 3,0 e 5,0 ha, com TIR de 10 e 18\%, respectivamente (Tabela 10). Para ambos os sistemas, observou-se que aqueles que utilizaram cerca de tela apresentaram maiores custos de implantação e de manutenção em relação à cerca elétrica (Tabelas 2 e 4). Para ambos os sistemas, o item que mais onerou a estrutura de custo de implantação foi a compra e o manejo dos animais, cuja participação no custo total para exploração com cerca elétrica foi de 45,44; 43,80 e 44,24\% e com cerca de tela de 40,99; 38,52 e 38,71\% para 1,0; 3,0 e 5,0 ha, respectivamente. Quanto ao custo total de manutenção, os custos com a aquisição de animais representaram cerca de 49,31; 58,15 e
60,32\%, para o sistema de cerca elétrica, enquanto que para o sistema com cerca de tela esse item representou 48,71; 57,33 e 59,44\% dos custos, considerando as áreas de 1,0; 3,0 e 5,0 ha, respectivamente. Os custos com a ração concentrada foi o terceiro item que mais onerou a atividade, representando não mais do que $17 \%$ dos custos totais de manutenção dos sistemas simulados (Tabela 4).

Para o sistema de produção com suplementação ao nível de 1,8\% PV, observou-se que à medida que se elevou o preço do produto, viabilizou-se a exploração de áreas a partir de 3,0 ha (Tabelas 11 e 12). Quando foi simulado o preço de venda variando entre R\$2,60 e 3,00/kg PV, a taxa interna de retorno (TIR) foi inferior à taxa de juros de oportunidade do capital para todos os tamanhos de pastagens e tipos de contenção avaliados. Com uma área de pastagem de 5,0 ha, o sistema só obteve retorno econômico com um preço de venda de $\mathrm{R} \$ 3,20 / \mathrm{kg} \mathrm{PV}$ para os dois tipos de contenção. Vale ressaltar que a suplementação com 1,8\% PV proporcionou maior ganho por área, sugerindo um efeito substitutivo, devido à maior proporção de concentrado na dieta total e com alta densidade energética, o que favoreceu o desenvolvimento da microbiota ruminal amilolítica. Esse possível aumento dos microrganismos amilolíticos acarreta redução do $\mathrm{pH}$ ruminal, inibindo a atividade da microbiota celulolítica, bastante sensível à queda do $\mathrm{pH}$, acarretando decréscimos no consumo de forragem (FERRELL, 1988; VAN SOEST, 1994) e aumentando a taxa de lotação pelo efeito substitutivo.

Com a exploração de até 3,0 ha com a suplementação de $1,8 \% \mathrm{PV}$, cerca elétrica e preço de R\$3,20/kg PV, o valor da TIR (9\%) foi superior ao da taxa de juros de oportunidade do capital. No entanto, considerando a exploração de 5,0 ha com cerca elétrica e preço de venda de $\mathrm{R} \$ 3,00 / \mathrm{kg} P V$, para uma taxa de juros de 8,75\%, o valor presente líquido (VPL) foi inferior a zero (Tabela 11); portanto, esse empreendimento não permitiu um retorno em relação ao custo de oportunidade do capital, ou seja, os benefícios não foram suficientes para compensar os custos de oportunidade de sacrificar outras alternativas de investimento. Ainda nesse sistema de produção, a TIR mostrou-se menor (1\%) à taxa de juros de oportunidade do capital, tornando o investimento economicamente inviável. A relação benefício/custo (B/C) desse sistema de produção mostrou que o valor presente dos benefícios é 
inferior aos dos custos, ou seja, para cada real aplicado no empreendimento, há decréscimo de R\$ 0,029 na receita. Somente com um preço de venda a partir de R \$3,20/kg PV o sistema mostrou rentabilidade, com uma B/C de apenas 1,036, VPL superior a zero e TIR (17\%) superior à taxa de juros de oportunidade do capital.

Para o sistema de produção com cerca de tela (Tabela 12), só foi verificada viabilidade econômica com preço de venda mais elevado (R\$ 3,20/kg PV), com B/C>1,0; VPL $>0$ e $R L$ positiva.

Para ambos os sistemas de produção, observou-se que aqueles que utilizaram cerca de tela apresentaram maiores custos de implantação e de manutenção em relação à cerca elétrica (Tabelas 2 e 4). Ainda para ambos os sistemas, os itens que mais oneraram a estrutura do custo de implantação foram a compra e manejo dos animais, seguido pela irrigação. Apesar de esse nível de suplementação ter apresentado elevada taxa de lotação (77 ovinos/ha) e rendimento de peso vivo por área (3633 kg PV/ha x ano), os custos de produção até o preço de venda de $\mathrm{R} \$$ 3,00/kg PV foram elevados frente ao nível de produção, por ter se trabalhado com animais de baixo potencial de produção (SPRD), castrados e com elevada idade (entre 1 ano e 1 ano e meio). À medida que a idade aumenta, os rendimentos são cada vez mais decrescentes, apesar de ainda existir ganho de peso, pois nesta fase, o animal demanda maiores consumos de matéria seca com a conversão alimentar cada vez pior, exigindo mais alimentos para produzir cada vez menos peso vivo, levando ao baixo ganho de peso e refletindo adversamente nos índices econômicos estudados.

Tabela 10. Índices econômicos para terminação de ovinos em pastagem de Panicum maximum cv. Tanzânia, irrigado com suplementação concentrada ao nível de 1,2\% PV em função de três tamanhos de área, cerca de tela e diferentes preços pagos ao produtor

\begin{tabular}{|c|c|c|c|c|c|c|c|c|}
\hline Ano & $\begin{array}{c}\text { Preço } \\
(\mathrm{R} \$ / \mathrm{kg} \mathrm{PV} \text {, }\end{array}$ & $\begin{array}{l}\text { Investimento } \\
(\mathrm{R} \$)\end{array}$ & $\begin{array}{l}\text { Custeio } \\
\text { (R\$/ano) }\end{array}$ & $\begin{array}{c}\mathrm{RB}^{1} \\
\text { (R\$/ano) }\end{array}$ & $\begin{array}{c}\mathrm{RL}^{2} \\
\text { (R\$/ano) }\end{array}$ & $\mathrm{B} / \mathrm{C}^{3}$ & $\begin{array}{l}\mathrm{VPL}^{4} \\
(\mathrm{R} \$)\end{array}$ & $\begin{array}{l}\mathrm{TIR}^{5} \\
(\%)\end{array}$ \\
\hline \multicolumn{9}{|c|}{ Sistema com cerca de tela, área de 1 ha } \\
\hline $\begin{array}{c}1 \\
2-10\end{array}$ & 2,6 & $\begin{array}{c}16.917,05 \\
-\end{array}$ & $\begin{array}{l}13.530,01 \\
27.061,01\end{array}$ & $\begin{array}{c}5.907,20 \\
21.086,00\end{array}$ & $\begin{array}{c}-24.539,86 \\
-5.975,01\end{array}$ & 0,693 & $-63.311,00$ & $*$ \\
\hline $\begin{array}{c}1 \\
2-10 \\
\end{array}$ & 2,8 & $\begin{array}{c}16.917,05 \\
-\end{array}$ & $\begin{array}{l}13.530,01 \\
27.061,01\end{array}$ & $\begin{array}{c}6.361,60 \\
22.708,00\end{array}$ & $\begin{array}{l}-24.085,46 \\
-4.353,01\end{array}$ & 0,746 & $-52.331,62$ & $*$ \\
\hline $\begin{array}{c}1 \\
2-10\end{array}$ & 3,0 & $\begin{array}{c}16.917,05 \\
-\end{array}$ & $\begin{array}{l}13.530,01 \\
27.061,01\end{array}$ & $\begin{array}{c}6.816,00 \\
24,330,00\end{array}$ & $\begin{array}{l}-23.631,06 \\
-2.731,01\end{array}$ & 0,799 & $-41.352,25$ & $*$ \\
\hline $\begin{array}{c}1 \\
2-10\end{array}$ & 3,2 & $\begin{array}{c}16.917,05 \\
-\end{array}$ & $\begin{array}{l}13.530,01 \\
27.061,01\end{array}$ & $\begin{array}{c}7.270,40 \\
25.952,00\end{array}$ & $\begin{array}{c}-23.176,66 \\
-1.109,01\end{array}$ & 0,853 & $-30.372,88$ & $*$ \\
\hline \multicolumn{9}{|c|}{ Sistema com cerca de tela, área de 3 ha } \\
\hline $\begin{array}{c}1 \\
2-10\end{array}$ & 2,6 & $\begin{array}{c}40.918,75 \\
-\end{array}$ & $\begin{array}{l}34.488,29 \\
68.976,57\end{array}$ & $\begin{array}{l}17.721,60 \\
63.258,00\end{array}$ & $\begin{array}{c}-57.685,44 \\
-5.718,57\end{array}$ & 0,819 & $-94.792,57$ & $*$ \\
\hline $\begin{array}{c}1 \\
2-10\end{array}$ & 2,8 & $\begin{array}{c}40.918,75 \\
-\end{array}$ & $\begin{array}{l}34.488,29 \\
68.976,57\end{array}$ & $\begin{array}{l}19.084,80 \\
68.124,00\end{array}$ & $\begin{array}{c}-56.322,24 \\
-852,57\end{array}$ & 0,882 & $-61.854,45$ & $*$ \\
\hline $\begin{array}{c}1 \\
2-10\end{array}$ & 3,0 & $\begin{array}{c}40.918,75 \\
-\end{array}$ & $\begin{array}{l}34.488,29 \\
68.976,57\end{array}$ & $\begin{array}{l}20.448,00 \\
72.990,00\end{array}$ & $\begin{array}{c}-54.959,04 \\
4.013,43\end{array}$ & 0,945 & $-28.916,33$ & $-5 \%$ \\
\hline $\begin{array}{c}1 \\
2-10\end{array}$ & 3,2 & $\begin{array}{c}40.918,75 \\
-\end{array}$ & $\begin{array}{l}34.488,29 \\
68.976,57\end{array}$ & $\begin{array}{l}21.811,20 \\
77.856,00\end{array}$ & $\begin{array}{c}-53.595,84 \\
8.879,43\end{array}$ & 1,008 & $4.021,79$ & $10 \%$ \\
\hline \multicolumn{9}{|c|}{ Sistema com cerca de tela, área de 5 ha } \\
\hline $\begin{array}{c}1 \\
2-10\end{array}$ & 2,6 & $\begin{array}{c}64.767,66 \\
-\end{array}$ & $\begin{array}{c}55.434,57 \\
110.869,14\end{array}$ & $\begin{array}{c}29.536,00 \\
105.430,00\end{array}$ & $\begin{array}{c}-90.666,23 \\
-5.439,14\end{array}$ & 0,850 & $-125.960,16$ & $*$ \\
\hline $\begin{array}{c}1 \\
2-10 \\
\end{array}$ & 2,8 & $\begin{array}{c}64.767,66 \\
- \\
\end{array}$ & $\begin{array}{c}55.434,57 \\
110.869,14 \\
\end{array}$ & $\begin{array}{c}31.808,00 \\
113.540,00 \\
\end{array}$ & $\begin{array}{c}-88.394,23 \\
2.670,86\end{array}$ & 0,915 & $-71.063,30$ & $-17 \%$ \\
\hline $\begin{array}{c}1 \\
2-10\end{array}$ & 3,0 & $\begin{array}{c}64.767,66 \\
-\end{array}$ & $\begin{array}{c}55.434,57 \\
110.869,14\end{array}$ & $\begin{array}{c}34.080,00 \\
121.650,00\end{array}$ & $\begin{array}{c}-86.122,23 \\
10.780,86\end{array}$ & 0,981 & $-16.166,43$ & $4 \%$ \\
\hline $\begin{array}{c}1 \\
2-10\end{array}$ & 3,2 & $\begin{array}{c}64.767,66 \\
-\end{array}$ & $\begin{array}{c}55.434,57 \\
110.869,14\end{array}$ & $\begin{array}{c}36.352,00 \\
129.760,00\end{array}$ & $\begin{array}{c}-83.850,23 \\
18.890,86\end{array}$ & 1,046 & $38.730,44$ & $18 \%$ \\
\hline
\end{tabular}

${ }^{1}$ Receita bruta; ${ }^{2}$ Receita líquida; ${ }^{3}$ Relação benefício/custo; ${ }^{4}$ Valor presente líquido; ${ }^{5}$ Taxa interna de retorno.

* Não foi possível encontrar uma solução. 
Tabela 11. Índices econômicos para terminação de ovinos em pastagem de Panicum maximum cv. Tanzânia, irrigado com suplementação concentrada ao nível de 1,8\% PV em função de três tamanhos de área, cerca elétrica e diferentes preços pagos ao produtor

\begin{tabular}{|c|c|c|c|c|c|c|c|c|}
\hline Ano & $\begin{array}{l}\text { Preço } \\
(\mathrm{R} \$ / \mathrm{kg}\end{array}$ & $\begin{array}{l}\text { Investimento } \\
(\mathrm{R} \$)\end{array}$ & $\begin{array}{c}\text { Custeio } \\
\text { (R\$/ano) }\end{array}$ & $\begin{array}{c}\mathrm{RB}^{\mathrm{I}} \\
\text { (R\$/ano) }\end{array}$ & $\begin{array}{c}\mathrm{RL}^{2} \\
\text { (R\$/ano) }\end{array}$ & $\mathrm{B} / \mathrm{C}^{5}$ & $\begin{array}{l}\mathrm{VPL}^{4} \\
(\mathrm{R} \$)\end{array}$ & $\begin{array}{l}\mathrm{TIR}^{5} \\
(\%)\end{array}$ \\
\hline \multicolumn{9}{|c|}{ Sistema com cerca elétrica, área 1ha } \\
\hline 1 & 2,6 & $15.587,35$ & $15.453,52$ & $6.411,60$ & $-24.629,27$ & 0,703 & $-68.727,38$ & * \\
\hline $2-10$ & & - & $30.907,04$ & 24.111,10 & $-6.795,94$ & & & \\
\hline 1 & 2,8 & $15.587,35$ & $15.453,52$ & $6.904,80$ & $-24.136,07$ & 0,757 & $-56.199,24$ & * \\
\hline $2-10$ & & - & $30.907,04$ & $25.965,80$ & $-4.941,24$ & & & \\
\hline 1 & 3,0 & $15.587,35$ & $15.453,52$ & $7.398,00$ & $-23.642,87$ & 0,811 & $-43.671,10$ & * \\
\hline $2-10$ & & - & $30.907,04$ & $27.820,50$ & $-3.086,54$ & & & \\
\hline 1 & 3,2 & $15.587,35$ & $15.453,52$ & $7.891,20$ & $-23149,67$ & 0,866 & $-31.142,97$ & * \\
\hline $2-10$ & & - & $30.907,04$ & $29.675,20$ & $-3.086,54$ & & & \\
\hline \multicolumn{9}{|c|}{ Sistema com cerca elétrica, área de 3 ha } \\
\hline 1 & 2,6 & $36.966,89$ & $40.263,81$ & $19.234,80$ & $-57.995,90$ & 0,815 & $-111.167,87$ & * \\
\hline $2-10$ & & - & $80.527,61$ & $72.333,30$ & $-8.194,31$ & & & \\
\hline 1 & 2,8 & $36.966,89$ & $40.263,81$ & $20.714,40$ & $-56.516,30$ & 0,877 & $-73.583,46$ & * \\
\hline $2-10$ & & - & $80.527,61$ & $77.897,40$ & $-2.630,21$ & & & \\
\hline 1 & 3,0 & $36.966,89$ & $40.263,81$ & $22.194,00$ & $-55.036,70$ & 0,940 & $-35.999,05$ & $-10 \%$ \\
\hline $2-10$ & & - & $80.527,61$ & $83.461,50$ & 2.933,89 & & & \\
\hline 1 & 3,2 & $36.966,89$ & $40.263,81$ & $23.673,60$ & $53.557,10$ & 1,00 & $1.585,36$ & $9 \%$ \\
\hline $2-10$ & & - & $80.527,61$ & $89.025,60$ & 8.497,99 & & & \\
\hline \multicolumn{9}{|c|}{ Sistema com cerca elétrica, área de 5 ha } \\
\hline 1 & 2,6 & $58.304,22$ & $65.073,06$ & $32.058,00$ & $-91.319,28$ & 0,841 & $\begin{array}{l}-153.551,67 \\
\end{array}$ & * \\
\hline $2-10$ & & - & $130.146,11$ & $120.555,50$ & $9.590,61$ & & & \\
\hline 1 & 2,8 & $58.304,22$ & $65.073,06$ & $34.524,00$ & $-88.853,28$ & 0,906 & $-90.910,98$ & * \\
\hline $2-10$ & & - & 130.146,11 & $129.829,00$ & $-317,11$ & & & \\
\hline 1 & 3,0 & $58.304,22$ & $65.073,06$ & $36.990,00$ & $-86.387,28$ & 0,971 & $-28.270,30$ & $1 \%$ \\
\hline $2-10$ & & - & $130.146,11$ & $139.102,50$ & $8.956,39$ & & & \\
\hline 1 & 3,2 & $58.304,22$ & $65.073,06$ & $39.456,00$ & $-89.921,28$ & 1,036 & $-34.370,39$ & $17 \%$ \\
\hline $2-10$ & & - & $130.146,11$ & $148.376,00$ & $18.229,89$ & & & \\
\hline \multirow{3}{*}{\multicolumn{9}{|c|}{$\begin{array}{l}{ }^{1} \text { Receita bruta; }{ }^{2} \text { Receita líquida; }{ }^{3} \text { Relação benefício/custo; }{ }^{4} \text { Valor presente líquido; }{ }^{5} \text { Taxa interna de retorno. } \\
\text { * Não foi possível encontrar uma solução. } \\
\text { Tabela 12. Índices econômicos para terminação de ovinos em pastagem de Panicum maximum cv. Tanzânia, irrigado com } \\
\text { suplementação concentrada ao nível de } 1,8 \% \text { PV em função de três tamanhos de área, cerca de tela e diferentes preços pagos ao } \\
\text { produtor }\end{array}$}} \\
\hline & & & & & & & & \\
\hline & & & & & & & & \\
\hline Ano & Preço & Investimento & Custeio & $\mathrm{RB}^{1}$ & $\mathrm{RL}^{2}$ & $\mathrm{~B} / \mathrm{C}^{3}$ & $\mathrm{VPL}^{4}$ & $\mathrm{TIR}^{5}$ \\
\hline & $(\mathrm{R} \$ / \mathrm{kg} \mathrm{PV})$ & $(\mathrm{R} \$)$ & (R\$/ano) & (R\$/ano) & (R\$/ano) & & $(\mathrm{R} \$)$ & $(\%)$ \\
\hline \multicolumn{9}{|c|}{ Sistema com cerca de tela, área de 1 ha } \\
\hline 1 & 2,6 & $17.243,32$ & $15.619,27$ & $6.411,60$ & $-26.450,99$ & 0,691 & $-72.700,05$ & * \\
\hline $2-10$ & & - & $31.238,53$ & $24.111,10$ & $-7.127,43$ & & & \\
\hline 1 & 2,8 & $17.243,32$ & $15.619,27$ & $6.904,80$ & $-25.957,79$ & 0,745 & $-60.171,91$ & * \\
\hline $2-10$ & & - & $31.238,53$ & $25.965,80$ & $-5.272,73$ & & & \\
\hline 1 & 3,0 & $17.243,32$ & $15.619,27$ & 7.398,00 & $-25.464,59$ & 0,798 & $-47.643,77$ & $*$ \\
\hline $2-10$ & & - & $31.238,53$ & $27.820,50$ & $-3.418,03$ & & & \\
\hline 1 & 3,2 & $17.243,32$ & $15.619,27$ & 7.891,20 & $-24.971,39$ & 0,851 & $-35.115,64$ & $*$ \\
\hline $2-10$ & & - & $31.238,53$ & $29.675,20$ & $-1.563,33$ & & & \\
\hline \multicolumn{9}{|c|}{ Sistema com cerca de tela, área de 3 ha } \\
\hline 1 & 2,6 & $41.897,56$ & $40.754,57$ & $19.234,80$ & $-63.417,33$ & 0,799 & $-122.958,22$ & * \\
\hline $2-10$ & & - & $81.509,13$ & $72.333,30$ & $-9.175,83$ & & & \\
\hline 1 & 2,8 & 41.897,56 & $40.754,57$ & $20.714,40$ & $-21.183,16$ & 0,860 & - 85.373,81 & $*$ \\
\hline $2-10$ & & - & $81.509,13$ & $77.897,40$ & $-3.611,73$ & & & \\
\hline 1 & 3,0 & $41.897,56$ & $40.754,57$ & $22.194,00$ & $-60.458,13$ & 0,922 & - 47.789,40 & $-17 \%$ \\
\hline $2-10$ & & - & $81.509,13$ & $83.461,50$ & $1.952,37$ & & & \\
\hline 1 & 3,2 & $41.897,56$ & $40.754,57$ & $23.673,60$ & $-58.978,53$ & 0,983 & - 10.204,99 & $5 \%$ \\
\hline $2-10$ & & - & $81.509,13$ & $89.025,60$ & 7.516,47 & & & \\
\hline \multicolumn{9}{|c|}{ Sistema com cerca de tela, área de 5 ha } \\
\hline 1 & 2,6 & $66.399,01$ & $65.878,37$ & $32.058,00$ & $-100.219,38$ & 0,825 & $-172.902,91$ & * \\
\hline $2-10$ & & - & $131.756,73$ & $120.555,50$ & $-11.201,23$ & & & \\
\hline 1 & 2,8 & 66.399,01 & 65.878,37 & $34.524,00$ & $-97.753,38$ & 0,888 & $-110.262,23$ & $*$ \\
\hline $2-10$ & & - & $131.756,73$ & $129.829,00$ & $-1.927,73$ & & & \\
\hline 1 & 3,0 & 66.399,01 & 65.878,37 & $36.990,00$ & $-95.287,38$ & 0,952 & $-47.621,54$ & $-4 \%$ \\
\hline $2-10$ & & - & $131.756,73$ & $139.102,50$ & 7.345,77 & & & \\
\hline 1 & 3,2 & 66.399,01 & 65.878,37 & $39.456,00$ & $-92.821,38$ & 1,015 & $-15.019,14$ & $12 \%$ \\
\hline $2-10$ & & - & $131.756,73$ & $148.376,00$ & $16.619,27$ & & & \\
\hline
\end{tabular}

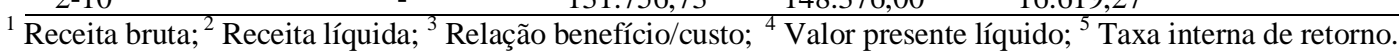

* Não foi possível encontrar uma solução. 
Para os sistemas que utilizaram suplementação, os dados mostraram que só é viável suplementar os animais quando o preço pago pelo produto for superior a $\mathrm{R} \$ 3,00 / \mathrm{kg}$ PV, em alguns casos com áreas superiores a 5 ha (sistema com cerca de tela). Somente a partir desse valor o ganho adicional proporcionado pela suplementação será suficiente para cobrir os custos com os insumos. Para os níveis de preço entre $\mathrm{R} \$ 3,00$ e 3,20/kg PV, a suplementação superior a $0,6 \% \mathrm{PV}$ reduz gradativamente a receita líquida e piora todos os indicadores econômicos.

Destaca-se que os resultados dessa pesquisa foram obtidos a partir dos dados oriundos da estação seca do ano, devendo-se, portanto, serem realizadas avaliações durante a estação chuvosa. Além disso, nessa pesquisa foram utilizados animais SPRD, com elevada idade e castrados, levando ao baixo desempenho produtivo, que aliado à elevada ocorrência de parasitas gastrintestinais, repercutiu adversamente na rentabilidade do sistema.

Nesse contexto, devem ser utilizados ovinos mais jovens e em pleno crescimento, proporcionando elevado ganho de peso e maiores rendimentos por área, maior rotatividade do sistema, e consequentemente, maior número de lotes terminados por ano, diminuindo riscos e refletindo em melhores índices econômicos.

Portanto, ficou demonstrado que a intensificação dos sistemas de produção de carne ovina em pastagens no Semi-árido Brasileiro, tendo em vista a utilização do método de lotação rotativa, adubação, irrigação e suplementação alimentar durante a estação seca, trouxe benefícios com melhores índices de produtividade dos rebanhos, com possibilidades de ampliar e diversificar a oferta de carne para a demanda interna e fortalecer ainda mais a competitividade existente entre os exportadores de carne no mercado internacional.

\section{CONCLUSÕES}

Produção de ovinos em áreas irrigadas de 1 ha são inviáveis, tornando-se viável para áreas com mais de 3 ha e preço de venda acima de $\mathrm{R} \$ 3,20 / \mathrm{kg}$ $\mathrm{PV}$ ou acima de $\mathrm{R} \$ 3,00 / \mathrm{kg}$ PV para 5,0 ha.

O uso de cerca elétrica é mais viável economicamente que a cerca de tela em qualquer nível de suplementação ou tamanho da área.

Para que haja viabilidade econômica utilizando o sistema testado, há necessidade de utilização de animais de ótimo potencial de ganho para aumentar a rotatividade do sistema e gerar maior lucratividade.

\section{REFERÊNCIAS}

ALMEIDA JÚNIOR, G.A.; COSTA, C.; MONTEIRO, A.L.G.; GARCIA, C.A.; MUNARI, D.P. NERES, M.A. Desempenho, características de carcaça e resultado econômico de cordeiros criados em creep feeding com silagem de grãos úmidos de milho. Revista Brasileira de Zootecnia, v. 33, n.4, p. 1048-1059, 2004.

CANZIANI, J.R.F. O cálculo e a análise do custo de produção para fins de gerenciamento e tomada de decisão nas propriedades rurais. Curitiba: DERE/SCA/UFPR, 2005. 19p. (Material Didático).

CARVALHO, D.M.G.; ZEVOUDAKIS, J.T.; CABRAL, L.S.; OLIVEIRA, A.A.; KOSCHECK, J.F.W.; BENATTI, J.M.B.; SILVA, J.J. Suplementação de bovinos em sistema de pastejo: aspectos relacionados à forragem e ao uso de fontes alternativas de energia para suplementos múltiplos. UNICiências, v. 14, n. 2, p. 241-270, 2010.

CUTRIM JÚNIOR, J.A.A.; CAMPOS, R.T. Avaliação econômica de diferentes sistemas de produção de leite a pasto. In: CONGRESSO DA SOCIEDADE BRASILEIRA DE ECONOMIA, ADMINISTRAÇÃO E SOCIOLOGIA RURAL, 48, 2010, Campo Grande. Anais... Campo Grande: SOBER, 2010. p.1-16. Disponível em http://www.sober.org.br/palestra/15/518.pdf, acesso em setembro 2011.

EMBRAPA - Empresa brasileira de pesquisa agropecuária - Embrapa. Sistema brasileiro de classificação dos solos. Brasília: CNPS, 1999, 412 $p$.

EUCLIDES, V.P.B. 2000. Alternativas para intensificação da produção de carne bovina em pastagem. Campo Grande: Embrapa Gado de Corte, 65 p. Diponível em http://www.cnpgc.embrapa.br/publicacoes/naoseriad as/cursosuplementacao/manejo/index.html, acesso em setembro 2011.

EUCLIDES, V.P.B.; EUCLIDES FILHO, K.; ARRUDA, Z.J.; FIGUEIREDO, G.R. Desempenho de novilhos em pastagens de Brachiaria decumbens submetidos a diferentes regimes alimentares. Revista Brasileira de Zootecnia, v. 27, n. 2, p. 246-254, 1998.

FARIA, V.P.; HUBER, J.T. Effect of dietary protein and energy-levels on rumen fermentation in Holsteins-Steers. Journal of Animal Science, v.58, p.452-459, 1984.

FERRELL, C.L. Energy metabolism. In: CHURCH, D.C. (Ed.). The ruminant animal: digestive physiology and nutrition. Englewood Cliffs, NJ: Prentice Hall, 1988. p.250-268.

HODGSON, J. Grazing management: science into practice. Harlow: Longman Scientific \& Technical, 
203p. 1990.

FISHER, D.S. Defining the experimental unit in grazing trials. Journal of Animal Science, v. 77, n.1, p. 1-5, 2000.

POMPEU, R.C.F.F. Morfofisiologia do dossel e desempenho bioeconômico de ovinos em capim Tanzânia sob lotação rotativa com quatro níveis de suplementação concentrada. Fortaleza: UFC, 2006. 147 f. Dissertação (Mestrado em Zootecnia) Universidade Federal do Ceará/UFC, 2006. Disponível em http://www.neef.ufc.br/diss2006_robert.pdf, acesso em junho 2011 .

POMPEU, R.C.F.F.; CÂNDIDO, M.J.D.; NEIVA, J.N.M; ROGÉRIO, M.C.P.; CAVALCANTE, M.A.B.; SILVA, R.G. Desempenho de ovinos em capim-tanzânia sob lotação rotativa com quatro proporções de suplementação concentrada. Arquivo Brasileiro de Medicina Veterinária e Zootecnia, v. 51, n.5, p.1104-1111, 2009.

SILVA, R.G. Morfofisiologia do dossel e desempenho produtivo de ovinos em Panicum maximum (Jacq.) cv. Tanzânia sob três períodos de descanso. Fortaleza: UFC, 2004. 114 f. Dissertação (Mestrado em Zootecnia) Universidade Federal do Ceará/UFC, 2004. Disponível

em http://www.neef.ufc.br/desovitanz.pdf. Acesso em junho/2011

SILVA, R.G.; NEIVA, J.N.M.; CÂNDIDO, M.J.D.; LÔBO, R.N.B. Aspectos comportamentais e desempenho produtivo de ovinos mantidos em pastagens de capim-tanzânia manejado sob lotação intermitente. Ciência Animal Brasileira (UFG), v.8, p.609 - 620, 2007.

VAN SOEST, P.J. Nutritional ecology of the ruminant. Ithaca, NY: Cornell University, 1994. 476p.

VIDAL， M.F.; SILVA, R.G.; NEIVA, J.N.M.; CÂNDIDO, M.J.D.; SILVA, D.S.; PEIXOTO, M.J.A. Análise econômica da produção de ovinos em lotação rotativa em pastagem de capim tanzânia (Panicum maximum (Jacq)). Revista de Economia e Sociologia Rural, v.44, n.4, p.801-818, 2006. 